\title{
Pan-cancer adaptive immune resistance as defined by the Tumor Inflammation Signature (TIS): results from The Cancer Genome Atlas (TCGA)
}

\author{
Patrick Danaher', Sarah Warren ${ }^{1}$ (D), Rongze Lu², Josue Samayoa ${ }^{2}$, Amy Sullivan ${ }^{1}$, Irena Pekker ${ }^{1}$, Brett Wallden ${ }^{1}$, \\ Francesco M. Marincola ${ }^{2}$ and Alessandra Cesano ${ }^{1 *}$
}

\begin{abstract}
The Tumor Inflammation Signature (TIS) is an investigational use only (IUO) 18-gene signature that measures a pre-existing but suppressed adaptive immune response within tumors. The TIS has been shown to enrich for patients who respond to the anti-PD1 agent pembrolizumab. To explore this immune phenotype within and across tumor types, we applied the TIS algorithm to over 9000 tumor gene expression profiles downloaded from The Cancer Genome Atlas (TCGA). As expected based on prior evidence, tumors with known clinical sensitivity to anti-programmed cell death protein 1 (PD-1) blockade had higher average TIS scores. Furthermore, TIS scores were more variable within than between tumor types, and within each tumor type a subset of patients with elevated scores was identifiable although with different prevalence associated with each tumor type, the latter consistent with the observed clinical responsiveness to anti PD-1 blockade. Notably, TIS scores only minimally correlated with mutation load in most tumors and ranking tumors by median TIS score showed differing association to clinical sensitivity to PD-1/PD-1 ligand 1 (PD-L1) blockade than ranking of the same tumors by mutation load. The expression patterns of the TIS algorithm genes were conserved across tumor types yet appeared to be minimally prognostic in most cancers, consistent with the TIS score serving as a pan-cancer measurement of the inflamed tumor phenotype. Characterization of the prevalence and variability of TIS will lead to increased understanding of the immune status of untreated tumors and may lead to improved indication selection for testing immunotherapy agents.
\end{abstract}

Keywords: Checkpoint inhibition, Tumor inflammation signature (TIS), The Cancer Genome Atlas (TCGA), Gene signature

\section{Background}

Recognition of the importance of the tumor immune microenvironment in suppressing antitumor immunity has led to significant advances in tumor immunotherapy. Treatments are now available that overcome tumor cells' ability to evade immune detection and harness the "non-self"-directed specificity of the immune system to attack tumors across multiple cancer types. In addition, immunotherapies, unlike cytotoxic or targeted therapies, have the advantage of triggering a memory immune

\footnotetext{
* Correspondence: acesano@nanostring.com

${ }^{1}$ NanoString Technologies Inc, Seattle, WA, USA

Full list of author information is available at the end of the article
}

response that clinically manifests in specific, systemic, and durable antitumor effect.

Among the most promising therapeutic approaches to re-activating anti-tumor immunity is the pharmacological manipulation of physiologic immune checkpoints. Immune checkpoints refer to inhibitory pathways in the immune system crucial for maintaining self-tolerance and minimizing the possibility of chronic autoimmune inflammation. Exploitation of immune checkpoint pathways is a major mechanism by which tumors escape immune surveillance, and immune checkpoint blockade is the basis for the clinical anti-tumor activity of most of the currently approved immuno-oncology agents 
targeting CTLA-4 (ipilumimab) and programmed cell death protein 1 (PD-1) (nivolumab, pembrolizumab,) or PD-1 ligand 1 (PD-L1) (atezolizumab, durvalumab, and avelumab) [1].

Despite this progress, only a minority of patients with advanced/metastatic cancer respond to immune checkpoint inhibitors, thus exposing the remaining patients to potentially ineffective, toxic, and costly treatments. Therefore, biomarkers predicting response are needed to guide treatment decisions in the clinic and to enable clinical trials to succeed in populations where response is rare.

In this regard, increased PD-L1 expression (as measured by immunohistochemistry [IHC]) on the surface of tumor cells and/or immune cells, despite representing today the only form of approved companion diagnostics for immunotherapies targeting the PD-1 axis, has been shown to be only inconsistently associated with these agents' clinical benefit [1]. This may be due to limitations intrinsic to the analyte measured (i.e., significant cellular, spatial, and temporal heterogeneity) and the platform used (i.e., subjective interpretation) [2]. In addition, the drug-centric approach of independently developing a PD-L1 IHC assay for each anti-PD-1/PD-L1 agent has resulted in a lack of "gold standard" assay, complicating testing and decision making in the clinic.

Additional predictive biomarkers have been investigated for use in immuno-oncology. For example, abundance and location of tumor infiltrating lymphocytes has been proposed as biomarker [3]. The most advanced assay in use to date is the Immunoscore, an immunohistochemistry based assay which quantitates abundance and phenotype of $\mathrm{T}$ cells [4]. The Immunoscore has been shown to be highly prognostic in colorectal cancer (CRC) [5], but its utility as a predictive marker remains uncharacterized.

More recently, clinical trial data have demonstrated the utility of measuring microsatellite instability (MSI) status and/or DNA mismatch repair deficiency (dMMR) as predictive markers for response to PD-1 blockade independently from tumor cell of origin, resulting in the first FDA pan-cancer approval of a therapeutic in oncology (pembrolizumab) [6]. The association of response to PD-1 blockade in dMMR tumors was first observed in a single patient with MSI-hi CRC in the nivolumab trial MDX1106-03 [7]. This initial result was then extended to show that patients with $\mathrm{dMMR}$ tumors experiences $27 \%$ ORR in CRC and 43\% ORR in non-CRC after receiving pembrolizumab, demonstrating the predictive power of biomarker [8]. Recently, pembrolizumab has received FDA approval in all indications where a tumor has dMMR, although the companion diagnostic remains undefined. Unfortunately, dMMR occurs in approximately $5 \%$ of $\mathrm{CRC}$ and endometrial tumors, and is much less frequent in other indications.
Another approach to characterizing potential neoantigen load that can be applied to a wider spectrum of tumors is measurement of total tumor mutation burden (TMB). The earliest successes of checkpoint inhibitors were in melanomas and non-small cell lung cancers, two tumors that can have high mutation burden due to mutagen exposure (UV light and tobacco smoke). The correlation of TMB and response to checkpoint inhibitors was first demonstrated in lung cancer, which has a broad range of nonsynonymous mutations within the tumor [9]. Since then, it has been demonstrated that tumor types with higher median mutation burden tend to be more response to checkpoint inhibitors than tumors that harbor few mutations [10]. Today, a number of platforms to detect TMB are being developed for routine clinical application, most prominently the FoundationOne assay, which reports on mutation status of 324 genes [11].

Because of the complexity of tumor-immune interactions, efforts to capture this complexity via a single analyte such as PD-L1 expression as measured by IHC, or tumor mutation load as a surrogate of potential tumor antigenicity, yields limited and incomplete information about the complex and dynamic nature of the tumor-immune microenvironment.

More recently, gene expression in the tumor microenvironment, using RNA isolated from formalin-fixed paraffin-embedded (FFPE) pretreatment samples from patients undergoing anti-PD-1/PD-L1 pathway treatment have been described [12-14]. These signatures measure, using various technology platforms, different but highly correlated gene transcripts associated with the presence of an adaptive immune response that is peripherally suppressed, a phenotype that appears to be necessary, although not sufficient, for clinical benefit from PD-1/PD-L1 blockade. One of these signatures, described by Ayers et al. (2017) [12], was developed on the NanoString nCounter gene expression system (NanoString Technologies, Inc., Seattle, WA) in the context of pembrolizumab treatment as a pan-tumor determinant of response to PD-1-directed therapy. Samples were obtained at baseline from patients undergoing treatment with pembrolizumab in clinical trials of multiple distinct tumor types in a rigorous stepwise validation of the hypothesis that immune-related gene signatures can enrich for clinical response to PD-1 checkpoint blockade, including samples from KEYNOTE-001, KEYNOTE-006, and KEYNOTE-028. The final analytically validated, IUO-ready gene expression signature, named the Tumor Inflammation Signature (TIS), contains genes related to antigen presentation, chemokine expression, cytotoxic activity, and adaptive immune resistance (Table 1). A score is calculated as a weighted linear combination of the 18 genes' expression values normalized to 
Table 1 Genes in the Tumor Inflammation Signature

\begin{tabular}{|c|c|c|c|}
\hline TIS Biology & Gene & Protein & Function \\
\hline \multirow[t]{4}{*}{$\begin{array}{l}\text { Antigen Presenting } \\
\text { Cell Abundance }\end{array}$} & PSMB10 & PSB10 & $\begin{array}{l}\text { Immunoproteosome } \\
\text { Subunit }\end{array}$ \\
\hline & HLA-DQA1 & $\begin{array}{l}\text { MHC class } \\
\text { ॥ DQA1 }\end{array}$ & $\begin{array}{l}\text { MHC Class II Antigen } \\
\text { Presentation }\end{array}$ \\
\hline & HLA-DRB1 & $\begin{array}{l}\text { MHC class } \\
\text { II DRB1 }\end{array}$ & $\begin{array}{l}\text { MHC Class II Antigen } \\
\text { Presentation }\end{array}$ \\
\hline & CMKLR1 & CML1 & Chemokine Receptor \\
\hline \multirow[t]{3}{*}{$\begin{array}{l}\text { T Cell/ NK Cell } \\
\text { Abundance }\end{array}$} & HLA-E & HLAE & $\begin{array}{l}\text { Nonclassical Class I } \\
\text { Antigen Presentation }\end{array}$ \\
\hline & NKG7 & NKG7 & Cytolytic Granule Protein \\
\hline & CD8A & CD8A & MHC Class I Coreceptor \\
\hline \multirow[t]{6}{*}{ IFN Activity } & $\mathrm{CCL} 5$ & CCL5 & $\begin{array}{l}\text { Monocytes and Memory } T \\
\text { cells Chemoattractant }\end{array}$ \\
\hline & CXCL9 & CXCL9 & $\begin{array}{l}\text { Lymphocyte } \\
\text { Chemoattractant }\end{array}$ \\
\hline & CD27 & CD27 & Lymphocyte Activation \\
\hline & CXCR6 & CXCR6 & T cell Activation \\
\hline & IDO1 & IDO & $\begin{array}{l}\text { Inhibitor of T cell } \\
\text { Proliferation and Function }\end{array}$ \\
\hline & STAT1 & STAT1 & $\begin{array}{l}\text { Transcription Factor } \\
\text { Mediating IFN Response }\end{array}$ \\
\hline \multirow[t]{5}{*}{ T Cell Exhaustion } & TIGIT & TIGIT & Inhibitor of T cell Function \\
\hline & LAG3 & LAG3 & Inhibitor of T cell Function \\
\hline & CD274 & PD-L1 & Inhibitor of $\mathrm{T}$ cell Function \\
\hline & PDCD1LG2 & PD-L2 & Inhibitor of T cell Function \\
\hline & CD276 & $\mathrm{B} 7-\mathrm{H}_{3}$ & Inhibitor of T cell Function \\
\hline
\end{tabular}

stable housekeeper gene expression, and scores above a fixed threshold can be used to evaluate patients whose tumor would benefit from pembrolizumab administration. The TIS has been developed into a clinical trial assay running on the nCounter Analysis System which has been applied retrospectively in multiple immuno-oncology trials (KEYNOTE-180, KEYNOTE-181, KEYNOTE-158).

As TIS is a measure of pre-existing adaptive immunity that has been peripherally suppressed, we sought to explore how this immune phenotype distributes within and across tumor types, and how it correlates with other relevant variables such as mutation load, other gene expression signatures, and clinical outcomes in the absence of specific immune therapeutic intervention. For this purpose, we applied the TIS algorithm to gene expression data from The Cancer Genome Atlas (TCGA) database of primary tumors. The specific objectives of this study were a) to explore the distribution of TIS scores within and across a wide range of immunotherapy-naive primary tumors; b) to assess the TIS score's prognostic value; c) to evaluate the association between TIS score and mutation load; d) to contrast TIS scores with expression levels of immune checkpoint molecules targeted by current immuno-oncology drugs in development; and e) to identify gene expression patterns associated with low TIS score (i.e., "cold" tumors). Similar efforts to characterize presence and activity of the intratumoral immune response have been undertaken in the past [15-17], and this report now extends upon those findings by applying the signature which is the basis for a clinical assay across a spectrum of both solid and hematological malignancies.

\section{Experimental section TCGA data download}

Level 3 RSEM-normalized RNASeqV2 data and level 3 mutation packager calls were downloaded from TCGA database. Per standard practice and in alignment with the TIS algorithm, RNASeq data were log2-transformed to avoid extremely skewed gene expression distributions and to allow additive methods like linear regression to model fold-changes rather than absolute expression increases. Each patient's mutation load was calculated as the number of non-synonymous mutations and then $\log 2$-transformed before analysis.

Statistical methods:

\section{a. Calculation of TIS score}

To maximize fidelity of our computational TIS score calculation to the clinical nCounter TIS assay, we re-normalized the RSEM RNAseq data using the 10 reference ("housekeeping") genes used in the nCounter assay and performed a log2-transformation of the normalized values. Second, we computed TIS score as a linear combination of the 18 algorithm genes, calculating TIS $=\sum_{i=1}^{18} x_{i} w_{i}$, where $\mathrm{x}_{\mathrm{i}}$ is the $\mathrm{i}^{\text {th }}$ gene's $\log 2$-transformed, normalized expression level and $\mathrm{w}_{\mathrm{i}}$ is a predefined weight derived in Ayers et al. (2017) [12]. We applied the TIS algorithm to 9083 samples from 32 TCGA RNASeq datasets (Table 2).

\section{b. Association between TIS scores and overall survival}

In each cancer type's dataset, a univariate Cox proportional hazard model was fit predicting overall survival from continuous TIS score. Kaplan-Meier curves were drawn using the R library ggsurvplot.

\section{c. Association between transcriptome and TIS scores}

The R library GSA [18] was used to compute the extent of positive and negative association between Gene Ontology (GO) terms [19] and the TIS scores. GO term gene lists were obtained from the Molecular Signatures Database (MsigDb) [20]. The GSA procedure was applied separately to each TCGA dataset taking the input 
Table 2 TCGA Datasets Evaluated

\begin{tabular}{|c|c|c|}
\hline Symbol & $\mathrm{N}$ & Name \\
\hline ACC & 79 & Adrenocortical carcinoma \\
\hline BLCA & 396 & Bladder urothelial carcinoma \\
\hline BRCA & 1092 & Breast invasive carcinoma \\
\hline CESC & 301 & $\begin{array}{l}\text { Cervical squamous cell carcinoma and endocervical } \\
\text { adenocarcinoma }\end{array}$ \\
\hline $\mathrm{CHOL}$ & 36 & Cholangiocarcinoma \\
\hline COAD & 280 & Colon adenocarcinoma \\
\hline DLBC & 47 & Lymphoid neoplasm diffuse large B-cell lymphoma \\
\hline ESCA & 183 & Esophageal carcinoma \\
\hline GBM & 167 & Glioblastoma multiforme \\
\hline HNSC & 516 & Head and neck squamous cell carcinoma \\
\hline $\mathrm{KICH}$ & 65 & Kidney chromophobe \\
\hline KIRC & 530 & Kidney renal clear cell carcinoma \\
\hline KIRP & 270 & Kidney renal papillary cell carcinoma \\
\hline LAML & 163 & Acute myeloid leukemia \\
\hline LGG & 506 & Brain lower grade glioma \\
\hline $\mathrm{LIHC}$ & 361 & Liver hepatocellular carcinoma \\
\hline LUAD & 497 & Lung adenocarcinoma \\
\hline LUSC & 483 & Lung squamous cell carcinoma \\
\hline MESO & 87 & Mesothelioma \\
\hline OV & 264 & Ovarian serous cystadenocarcinoma \\
\hline PAAD & 179 & Pancreatic adenocarcinoma \\
\hline PCPG & 184 & Pheochromocytoma and paraganglioma \\
\hline PRAD & 493 & Prostate adenocarcinoma \\
\hline READ & 95 & Rectum adenocarcinoma \\
\hline SARC & 249 & Sarcoma \\
\hline SKCM & 463 & Skin cutaneous melanoma \\
\hline STAD & 409 & Stomach adenocarcinoma \\
\hline TGCT & 139 & Testicular germ cell tumors \\
\hline THCA & 504 & Thyroid carcinoma \\
\hline THYM & 118 & Thymoma \\
\hline UCS & 57 & Uterine carcinosarcoma \\
\hline UVM & 80 & Uveal melanoma \\
\hline
\end{tabular}

of the dataset's normalized, log2-transformed expression values as the predictor matrix, the dataset's TIS scores as the outcome, and GO terms as gene sets.

\section{Results}

TIS scores are highly variable across and within tumor types, and a subset of patients with elevated scores exists within each tumor type

Figure 1 shows TIS scores for all TCGA patients included in the analysis, with tumor types ordered by median TIS scores. While median TIS scores are higher in tumor types with higher rates of response to PD-1/ PD-L1 inhibitors (e.g., melanoma, renal cell cancer), and cancers with high mutation load (e.g., non-small cell lung cancer [NSCLC]), within each tumor type there is considerable inter-sample variability. This finding is consistent with a wide range of pre-existent adaptive immunity levels within different tumor types, and it raises the possibility that TIS scores may identify rare responders within tumor types that have low immunotherapy response rates, low median TIS scores, and low mutation burden.

In the clinical setting, in order to use the TIS score as a patient enrichment tool (i.e., identifying "hot" versus "cold" tumors), one or more pre-specified thresholds are needed. Based on TCGA TIS scores, the following thresholds, in diminishing order of stringency, could be reasonable choices depending on the clinical population and the competing desires for enrichment and broad selection: 6.72 is the median TIS score in lung adenocarcinomas and the 75th percentile of all of TCGA; 6.0 is the median TIS score in melanomas and the 61st percentile of all of TCGA; and 5.5 is the median TIS score in all TCGA datasets. Given an estimated offset of 1.3 score units between TIS scores in TCGA and in the IUO assay, these thresholds translate to approximately 8.02, 7.3 and 6.8 in the TIS IUO assay.

Checkpoint inhibitors currently have wider use in late-stage tumors than in first-line settings. Thus the distribution of anti-tumor immunity as measured by TIS score in only late-stage tumors is of interest. Additional file 1: Figure S7 replots (Fig. 1) using only patients with stage IV disease. Within tumor types where sufficient stage IV patients were available, (Fig. 1)'s ranking of tumor types by median TIS is broadly preserved in stage IV patients, as is the observation of great variability of TIS within all tumor types.

\section{Tumors with a high TIS score have shown clinical response to anti-PD-1 blockade}

Many of the tumor types with high median TIS values, in particular advanced/metastatic renal clear cell carcinoma [21], melanoma [22], lung tumors [23], and head and neck tumors [24], have shown clinical sensitivity to anti-PD-1 blockade (Additional file 2: Figure S1).

The kidney cancers' responsiveness to checkpoint blockade is well-predicted by TIS scores, but not by mutation burden (Fig. 1, highlighted in red text). Renal clear cell carcinoma (KIRC), an immunogenic tumor type in which immunotherapies such as IL-2 [25], IFN- $\alpha$ [26], and nivolumab [27] have shown clinical benefit in a subset of patients, had the second-highest median TIS scores but fairly low mutation load. In contrast, chromophobe renal cell carcinoma $(\mathrm{KICH})$ and kidney renal 


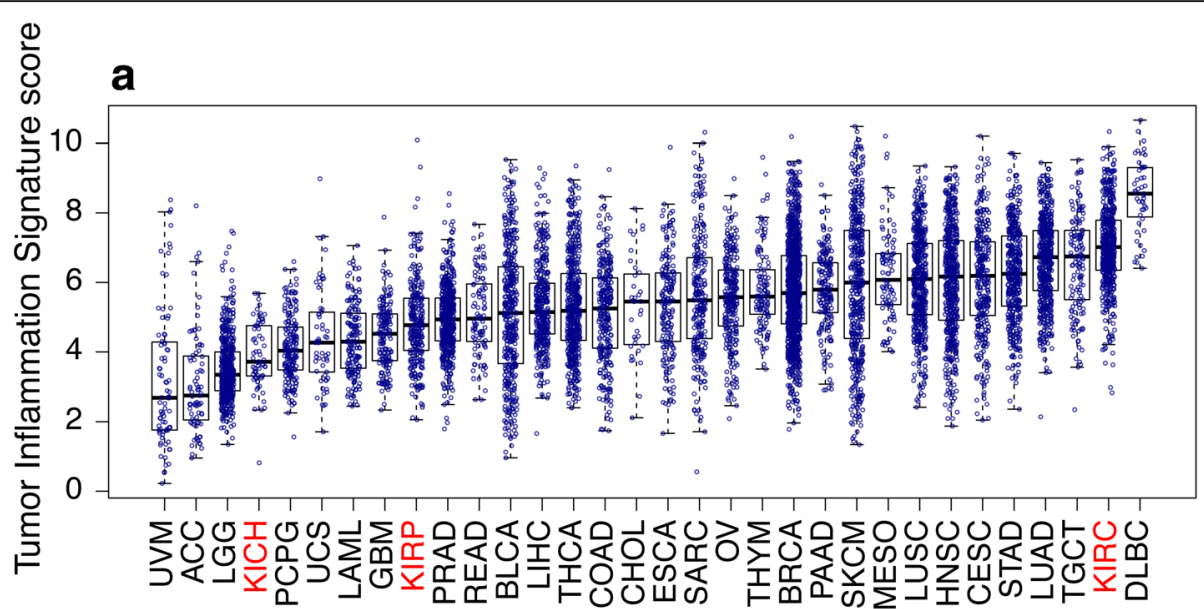

b

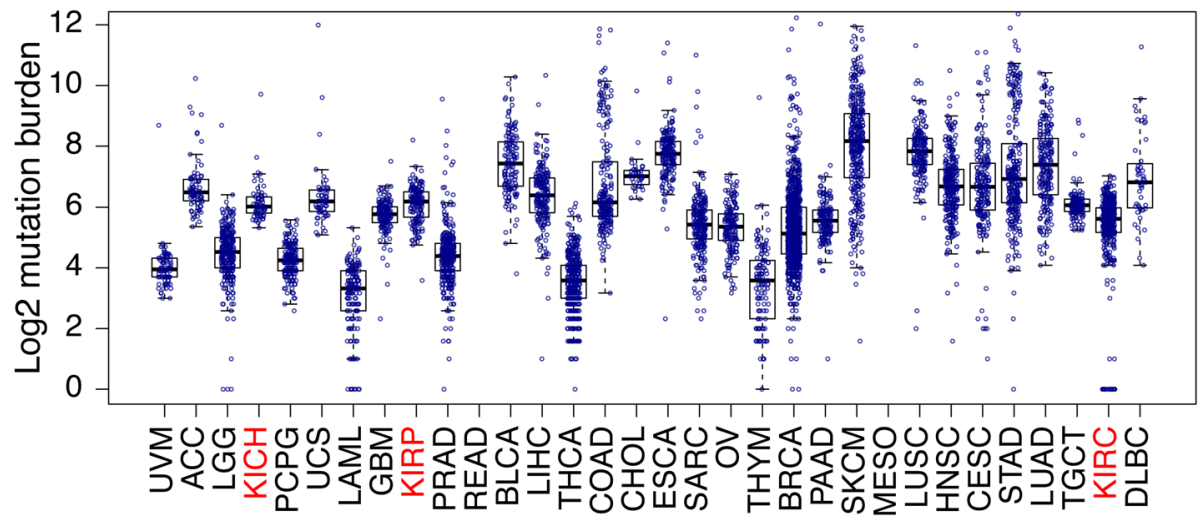

Fig. 1 TIS scores in all TCGA patients. a Boxplots and points show summary statistics and individual values of TIS scores in each cancer type, ranked by median TIS scores. $\mathbf{b}$ Boxplots of log2 mutation burden, showed based on ranking in (a)

papillary cell carcinoma (KIRP), which so far have shown less evidence of susceptibility to anti-PD-1/PD-L1 blockade, have low-ranking median TIS scores and similar median mutation burdens than clear cell carcinomas. Randomized trials investigating the performance of PD1 blockade in these tumors have not been reported to date, but anecdotal data suggests that response rates in the chromophobe subtype, which has the lowest median TIS of the 3 subtypes, has been particularly poor $[28,29]$. The finding of a high median TIS score in renal clear cell carcinomas and the efficacy of PD-1 blockade in this tumor type are consistent with other findings that the immunogenicity of renal clear cell carcinoma tumors cannot be explained solely by mutation or neoantigen load, but is highly correlated with MHC class I antigen presenting machinery expression [30].

Furthermore, some tumor types with a moderate TIS score (e.g., pancreatic tumors) have shown notably poor response to immunotherapy in an unselected population. These tumors are known to be highly infiltrated with myeloid cells which may act as external suppressors of anti-tumor immune responses that are not relieved by PD-1 checkpoint blockade [31], raising the possibility of future gene signatures that may by combined with TIS to further dissect immune responses.

\section{TIS scores are minimally correlated with mutation load within most cancer types}

Both TIS scores and mutation load have been investigated as predictive biomarkers for benefit of checkpoint inhibitors. These 2 biomarkers are weakly correlated Fig. 2a: the absolute value of their correlation is below 0.3 in all TCGA datasets, and in most TCGA datasets the $95 \%$ confidence interval for their correlation includes 0 Fig. 2b. The strongest correlations between TIS scores and $\log 2$ mutation load occurred in colon cancer, which is known to have a hypermutated and immunogenic microsatellite instability high (MSI-H) subtype, and in 


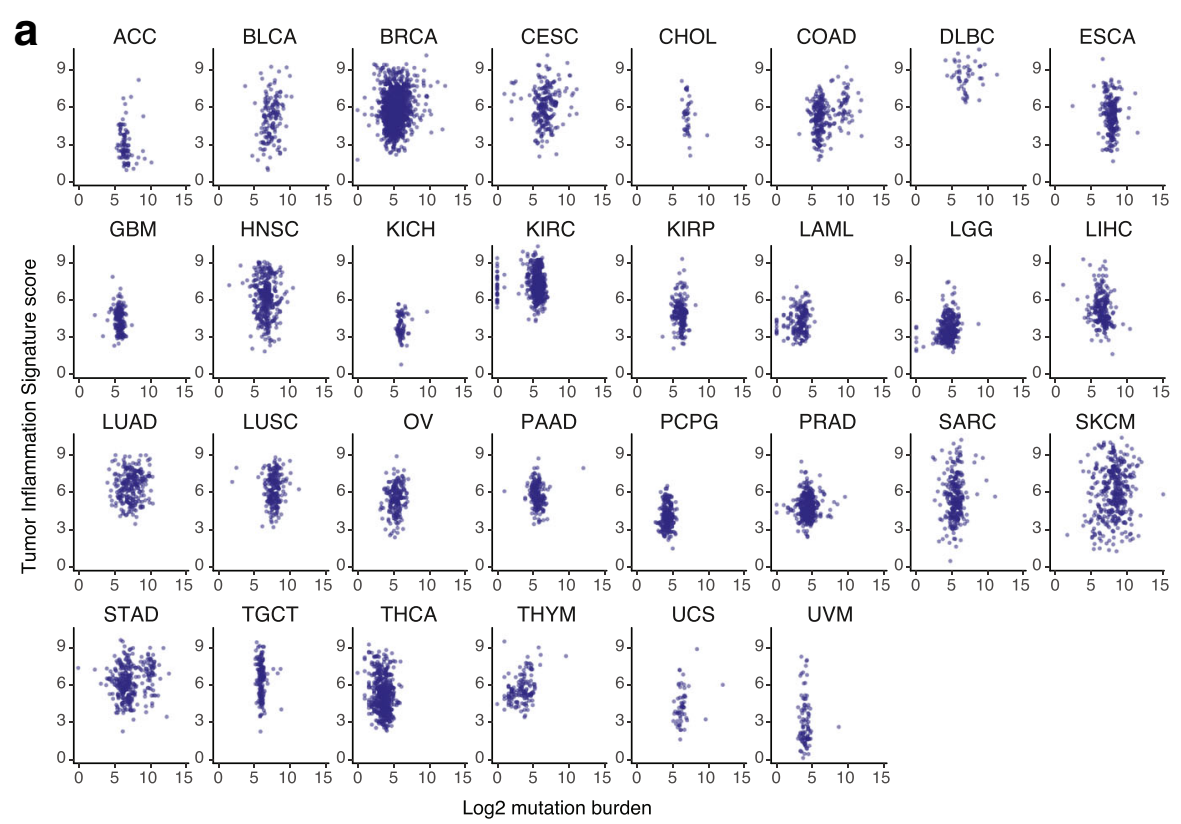

b

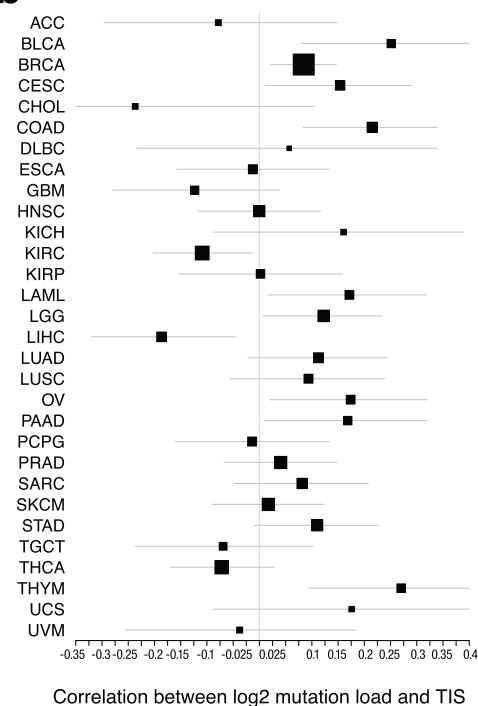

C

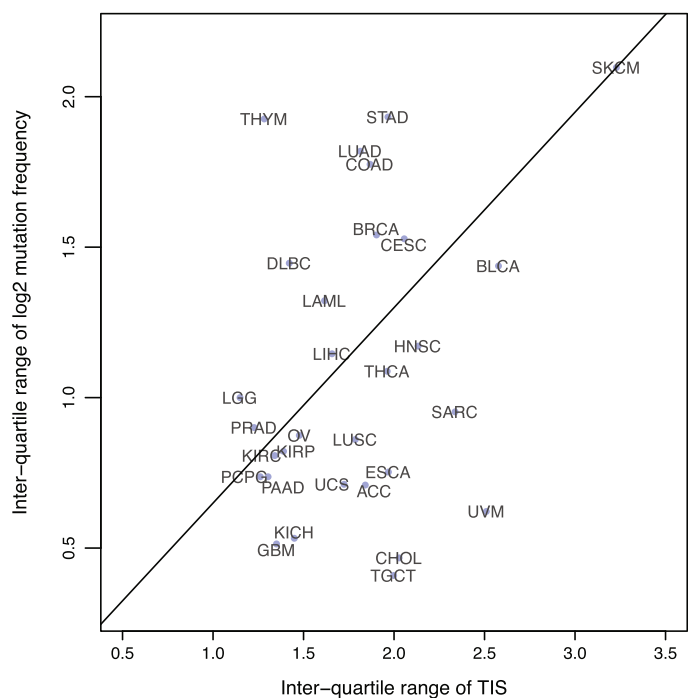

Fig. 2 Association between TIS scores and mutation load. a TIS score plotted against log2 mutation within each tumor type. b Point estimates and $95 \%$ confidence intervals for the correlation between TIS score and log2 mutation load within each tumor type. Box size represents the precision of the estimate with larger boxes indicating smaller standard errors; horizontal lines represent 95\% confidence intervals. c Interquartile range of TIS score and mutation load in each cancer type. To place cancer types in context, a line connects SKCM to the origin

thymomas and bladder cancer. Additional file 3: Figure S6 shows MSI-H status to be associated with elevated TIS scores in colon and stomach cancers. Liver hepatocellular carcinomas and kidney renal clear cell carcinoma showed statistically significant negative correlations between these biomarkers. A significant fraction of hepatocellular carcinomas are associated with hepatitis $\mathrm{B}$ or $\mathrm{C}$ virus infection, which may drive inflammation without the presence of a high number of mutations. There is negligible correlation between average mutation burden and average TIS scores across tumor types in TCGA datasets Fig. 2.

\section{The variability of TIS and mutation load are potential indicators of their predictive utility within cancer types} The predictive utility of TIS and mutation load within a given cancer type can only be definitively established by clinical trials with sample sizes large enough to profile 
response rates conditional on varying levels of both biomarkers. Until such data is available, large datasets like TCGA can offer important insights into the probable utility of these biomarkers in different cancer types.

A biomarker's predictive strength in a cancer depends on both the strength of its association with response and its variability. In particular, a biomarker that varies little within a population is less likely to successfully divide that population between responders and non-responders. Melanoma has a prominent role in the literature supporting TIS score and mutation load as predictors of response to checkpoint inhibitors; it also has a higher variability of both biomarkers than any other cancer type Fig. 2c. Some cancer types retain most of melanoma's TIS score variability while losing much greater variability in mutation load Fig. 2c, below the line, while others retain a greater proportion of melanoma's mutation load variability than its TIS score variability Fig. 2c, above the line. Since a biomarker's predictive strength in a cancer depends in part on its variability, Fig. 2c can support educated guesses on the performance of each putative predictive biomarker in any given tumor type (in the context of PD-1/PD-L1 pathway blockade). For example, the interquartile range of mutation load in lung squamous carcinoma (LUSC), head and neck squamous cell carcinoma (HNSC), and sarcomas (SARC) is approximately half as large as its interquartile range in SKCM, suggesting that the predictive utility of mutation burden observed in melanoma will be lower in these cancers. Therefore, in these tumor types and in the context of pharmacological blockade of the PD-1/PD-L1 pathway, TIS score may be a more useful predictive biomarker. Conversely, adenocarcinomas of the lung (LUAD), colon (COAD), and stomach (STAD) have high mutation burden variability but lower TIS variability than seen in melanomas. However, since biomarker utility also depends on how closely related the biomarker is to the mechanism of action of the drug, and since TIS measures transcriptional activity in the tumor microenvironment directly related to immune adaptive resistance, the TIS may provide additional utility in the context of mutation load, which is measuring potentially immune activating neoantigen expression, to enrich for clinical response to anti-PD1/PD-L1.

\section{Evaluation of prognostic value of TIS scores}

Since the TIS algorithm was developed in the context of single-arm studies of patients universally treated with single-agent pembrolizumab, its prognostic versus predictive value has yet to be established. In addition, considering that information about the nature, quantity, location, and functionality of immune infiltrates has been shown to contain prognostic information [3, 32-35], we explored the prognostic value of the TIS score in the absence of specific immune treatment. We performed univariate Cox regression predicting overall survival from TIS scores in each TCGA dataset. TIS scores were not statistically significantly prognostic in most cancers, with the notable exceptions of bladder cancer, cervical cancer, sarcomas, and melanoma, where a modest prognostic benefit (hazard ratio per unit of TIS score $>0.8$ ) of high TIS score was observed; and in renal papillary cell carcinoma, lower grade glioma, and pancreatic adenocarcinoma, where TIS was associated with poor prognosis (hazard ratios $>1.2$ ) Fig. 3. Of all these associations, only melanoma and lower grade glioma cancers had $p$-values corresponding to a False Discovery Rate [36] below 0.05 . These findings can aid interpretation of single-arm studies comparing survival in high and low TIS score patients treated with an immunotherapy.

\section{TIS in breast cancer: relation to subtype, survival, and mutation burden}

In order to explore the interaction between tumor-intrinsic genetic programs, tumor mutation load, and intratumoral immune response, we investigated the distribution of TIS scores and mutation burden within the intrinsic subtypes of breast cancers as defined by gene expression profiling, i.e., the PAM50 algorithm [37]. As shown in Fig. 4, TIS scores displayed considerable variability within all PAM50 subtypes. Average TIS scores were higher in the basal and Her2-enriched subtypes than in the luminal subtypes. However, between-subtype differences explain little of TIS's variability in breast cancer: the variance between the subtypes' means was $8 \%$ of the total variance of TIS score in the breast cancer samples.

Univariate Cox proportional hazard regression found no statistically significant association between TIS and overall survival in the TCGA breast cancer dataset. Cox models fit separately to each PAM50 subtype similarly showed no significant association. However, we observed that the subset of patients with the highest $10 \%$ of the TIS score range shows substantially improved prognosis (Additional file 9: Figure S5). This prognostic benefit of anti-tumor immunity is limited to the very highest TIS samples: the next highest $10 \%$ of TIS scores have prognosis equivalent to the lowest $80 \%$ of samples. These results echo those of Hendrickx et al. (2017) [38], who observed improved prognosis in breast cancers with the most favorable immune phenotype as measured by the immunologic constant of rejection (ICR). TIS scores and mutation load were minimally correlated within each PAM50 subtype Fig. 4, although Fig. 2 shows the weak correlation between mutation burden and TIS scores in breast cancer to be statistically significant. 

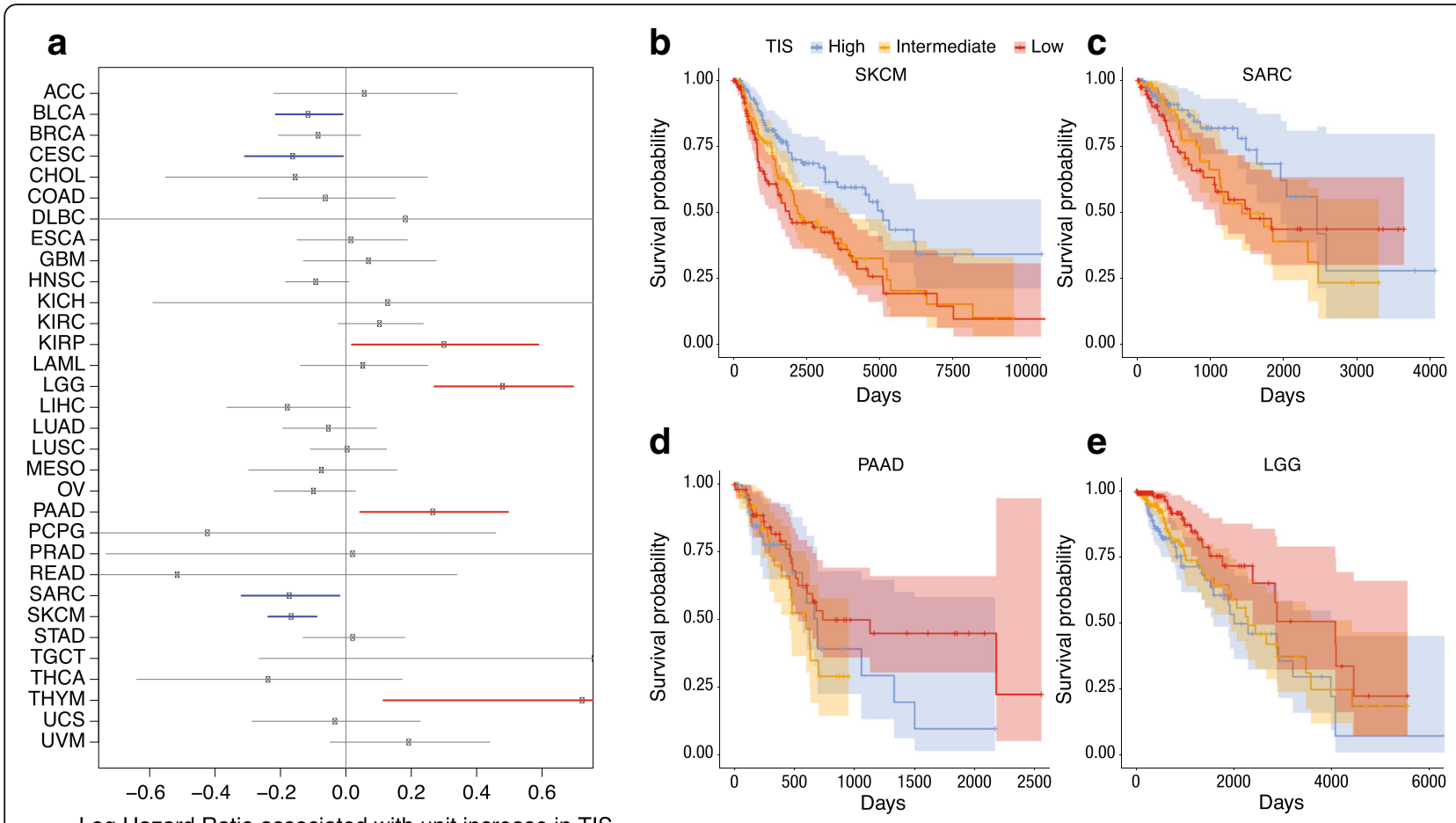

Log Hazard Ratio associated with unit increase in TIS

Fig. 3 Association between TIS score and overall survival in TCGA. a Forest plot showing log hazard ratio estimates and 95\% confidence intervals. Cancers in which TIS score is statistically significantly $(p<0.05)$ associated with good prognosis are highlighted in blue; significant associations with poor prognosis are in red. b-e Kaplan-Meier curves of overall survival split by TIS score tertiles within 4 selected tumor types: melanoma, sarcoma, pancreatic adenocarcinoma, and lower grade glioma

The TIS score reflects immune status rather than tumorspecific biology and is thus agnostic to tissue of origin

Tumors from different cells of origin tend to display highly divergent expression patterns, limiting the applicability of most gene expression algorithms across tumor types. In contrast, because the TIS depends primarily on genes expressed by immune cells or in response to immune signaling, it is plausible that its genes' expression levels are driven by the magnitude of a tumor's immune response and not by its cell of origin. To evaluate the applicability of the TIS algorithm across tumor types, we examined the extent to which the TIS genes' expression levels depend on tumor type versus overall immune status as measured by TIS algorithm.

Figure 5 shows each gene's association with TIS score within each cancer type. Apart from the few exceptions described below, all algorithm genes increase with TIS score, and each gene's lowess fit [39] to TIS score varies little between cancer types. This expression pattern is consistent with a model in which the algorithm genes measure immune-related transcriptomic activity and are minimally influenced by tumor type-specific expression. We generally do not observe expression patterns indicative of algorithm genes behaving differently across tumor types, for example a gene that is uniformly elevated or suppressed in a tumor type, or whose association with the TIS algorithm is different between cancer types.

There are exceptions to this pattern. First, the gene CD276, which codes for B7-H3, is uncorrelated with TIS score. Second, the 3 cancers in TCGA arising from "immune" cells, i.e., thymoma, acute myeloid leukemia (AML), and diffuse large B-cell lymphoma (DLBCL), all display expression patterns consistent with an effect of tumor type on the algorithm. In thymomas, CD8A expression, which has been shown to quantify CD8 T-cells in tumor samples [40], is high across all TIS scores and weakly negatively correlated with TIS score, likely because the tumor occurs in the thymus, the site of lymphocyte ( $T$ and $B$ cell) maturation. In AML, the trends for CD276, IDO1, and NKG7 all have substantially different intercepts and slopes than seen in the other tumor types. In DLBCL, CD27, HLA-DQA1, HLA-DRB, and PSMB10 are all high across all levels of TIS scores. The uniformly high TIS scores in DLBCL likely result from tumor-intrinsic expression of algorithm genes rather than truly high anti-tumor immunity; Fig. 5 details the TIS genes that have idiosyncratic expression in DLBCL. Close analysis of the coordinate expression of TIS genes permits appropriate interpretation of clinical settings where the signature can confidently be deployed. 

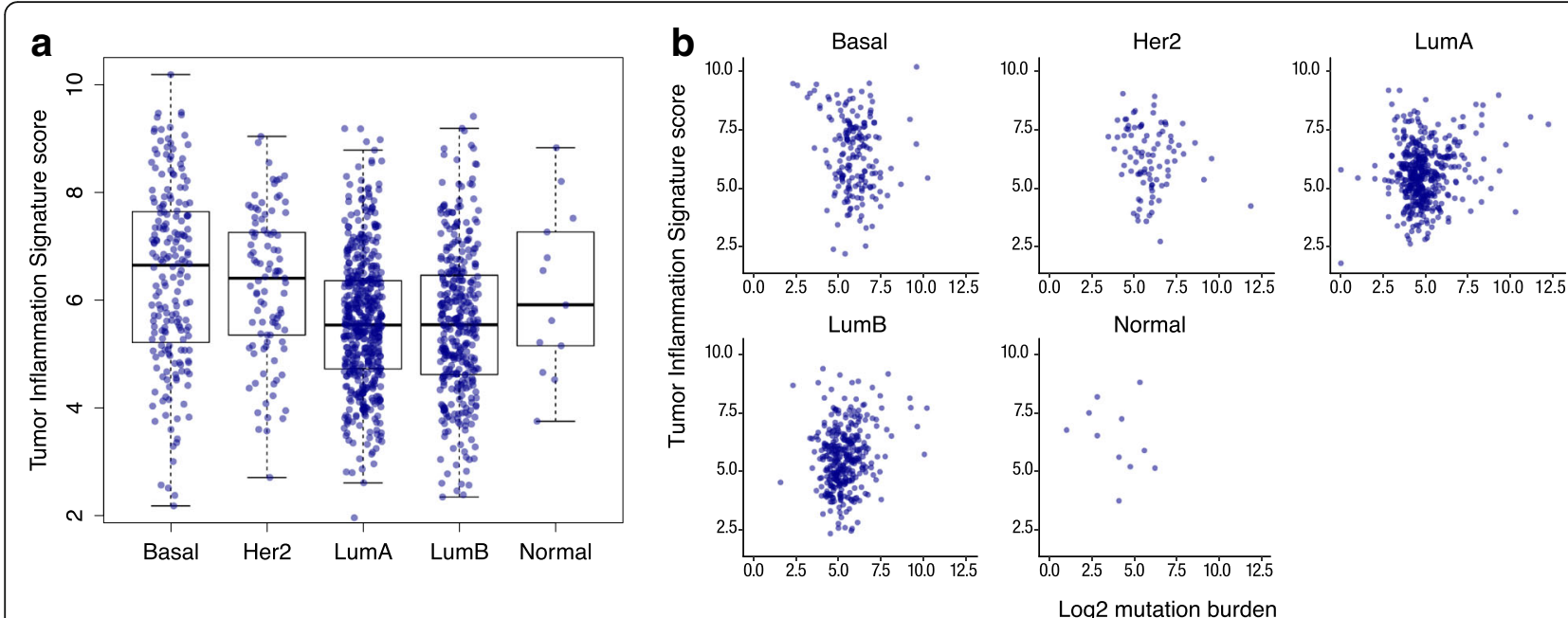

Fig. 4 TIS scores across PAM50 subtypes. a Distribution of TIS score within each PAM50 subtype. b TIS plotted against log2 mutation load in each subtype

These results indicate that the TIS score interpretation as a measure of the adaptive immune response may be biased in cancers that affect cells of the immune system. However, the unremarkable expression patterns of the majority of TIS genes in these cancers suggest that an adapted TIS score with the "offending" genes removed could perform as it does in other cancers.

To visualize the results of Fig. 5 in another way, we created a heat map of the TIS algorithm genes in all of TCGA Fig. 5.

Additional file 4: Figure S2 quantifies the visual evidence of Fig. 5. Linear mixed models were used to estimate the variance in each gene's expression attributable to tumor type. For most algorithm genes, the variance due to tumor type is a small proportion of total variance. The TIS normalization (housekeeping) genes show low variance within and across tumor types.

\section{Association between TIS scores and the transcriptome.}

Biological processes that are negatively correlated with TIS scores could represent targets for future immunotherapies. In order to identify these processes, we searched the whole transcriptome for gene sets with persistent negative correlations with TIS. To do so, we evaluated the association between single gene expression levels and TIS scores in each cancer type using univariate linear regression. Genes with strong positive associations with TIS scores were far more common and more strongly correlated with TIS than genes with negative associations (Additional file 8: Figure S3), which is expected, because genes expressed by immune cells will tend to be correlated with the total level of adaptive immunity. Because genes that are persistently negatively associated with TIS may indicate alternative immune-inhibitory mechanisms, we used gene set analysis (GSA) [18], which summarizes the extent to which a gene set is positively or negatively associated with a condition, to search for GO terms with strong negative associations with TIS scores. Additional file 5: Figure S4 shows the $50 \mathrm{GO}$ terms with the lowest GSA scores across all cancer types. Different tumor types have different GO terms associated with low TIS. The most frequent negatively-associated GO terms largely involve metabolism, which may reflect transcriptionally 'lean' tumors that have eluded immune detection as posited by Turan et al., (personal communication). Alternately, it may also reflect the suppressive effects of IFN signaling on cell growth that would lead to lower tumor cell metabolism in TIS-high tumors [41]. For each tumor type, Additional file 6: Table S1 lists the GO terms that are negatively associated with TIS scores, as defined by GSA scores $<1$.

\section{Association between TIS scores and immune checkpoint genes}

We specifically explored the association between TIS scores and genes coding for immunotherapy target molecules. Many of these genes are in the TIS algorithm, including IDO1, LAG3, PD-L1 (CD274), PD-L2 (PDCD1LG2), and TIGIT; however, no single gene contributes enough to TIS to cause a spurious correlation between its expression and TIS score. Every immunotherapy target examined is positively correlated with TIS scores Fig. 6, suggesting that TIS scores could be of predictive value for all inhibitors of these targets. CLTA4 is the greatest departure from this trend, possibly reflecting the unique role CTLA4 plays in limiting the initial priming of $\mathrm{T}$ cells rather than suppressing $\mathrm{T}$ cell function after activation Fig. 6. Additional file 7: Figure S8-S39 show TIS score versus individual checkpoint genes in all 


\section{a}
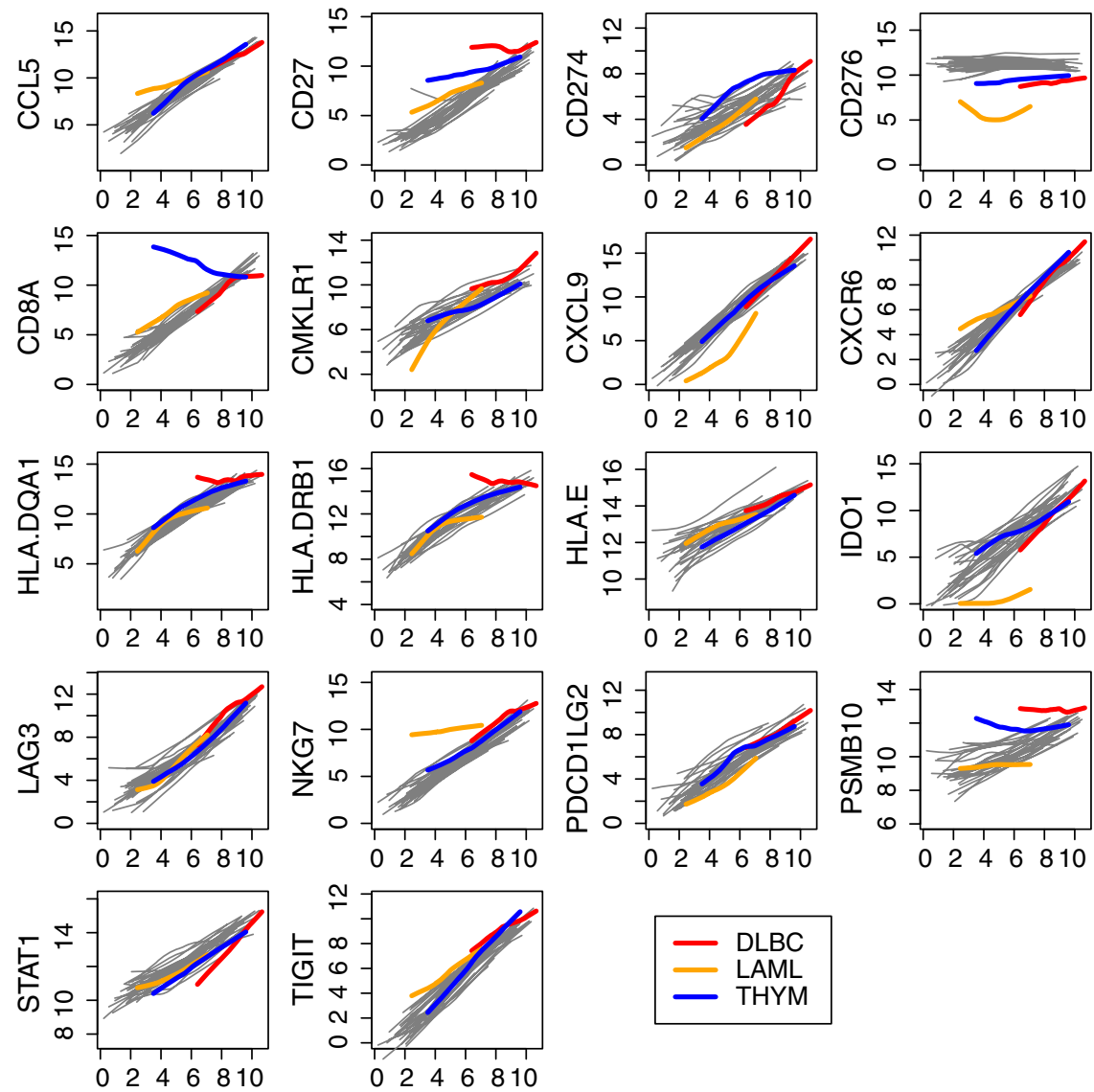

b

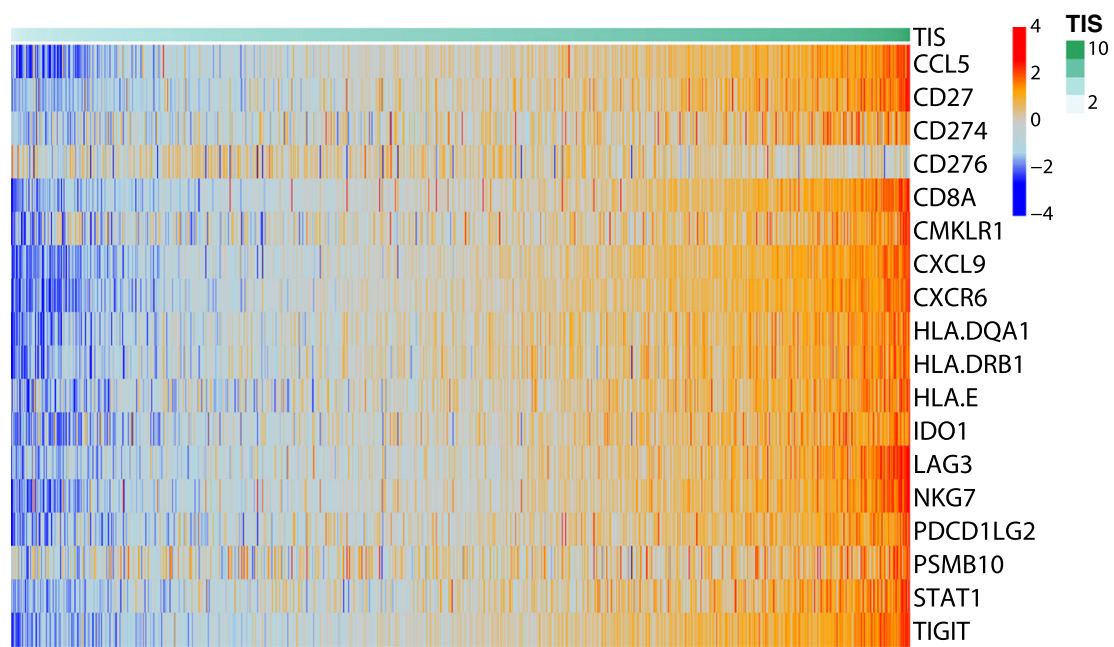

Fig. 5 Algorithm genes depend more on TIS score than on cancer type. a Each gene is plotted against TIS score, with separate lowess lines fit for each cancer type. Immune-derived tumors are highlighted; other solid tumors are shown with grey lines. A gene with no dependency on tumor type would have the same association with TIS score in each cancer type, and the lines for each cancer type would be perfectly overlapping. A gene with problematic dependency on cancer type would have lines with markedly different slopes, intercepts, or shapes. b Samples are ordered from lowest to highest TIS score. The top color bar shows TIS score 

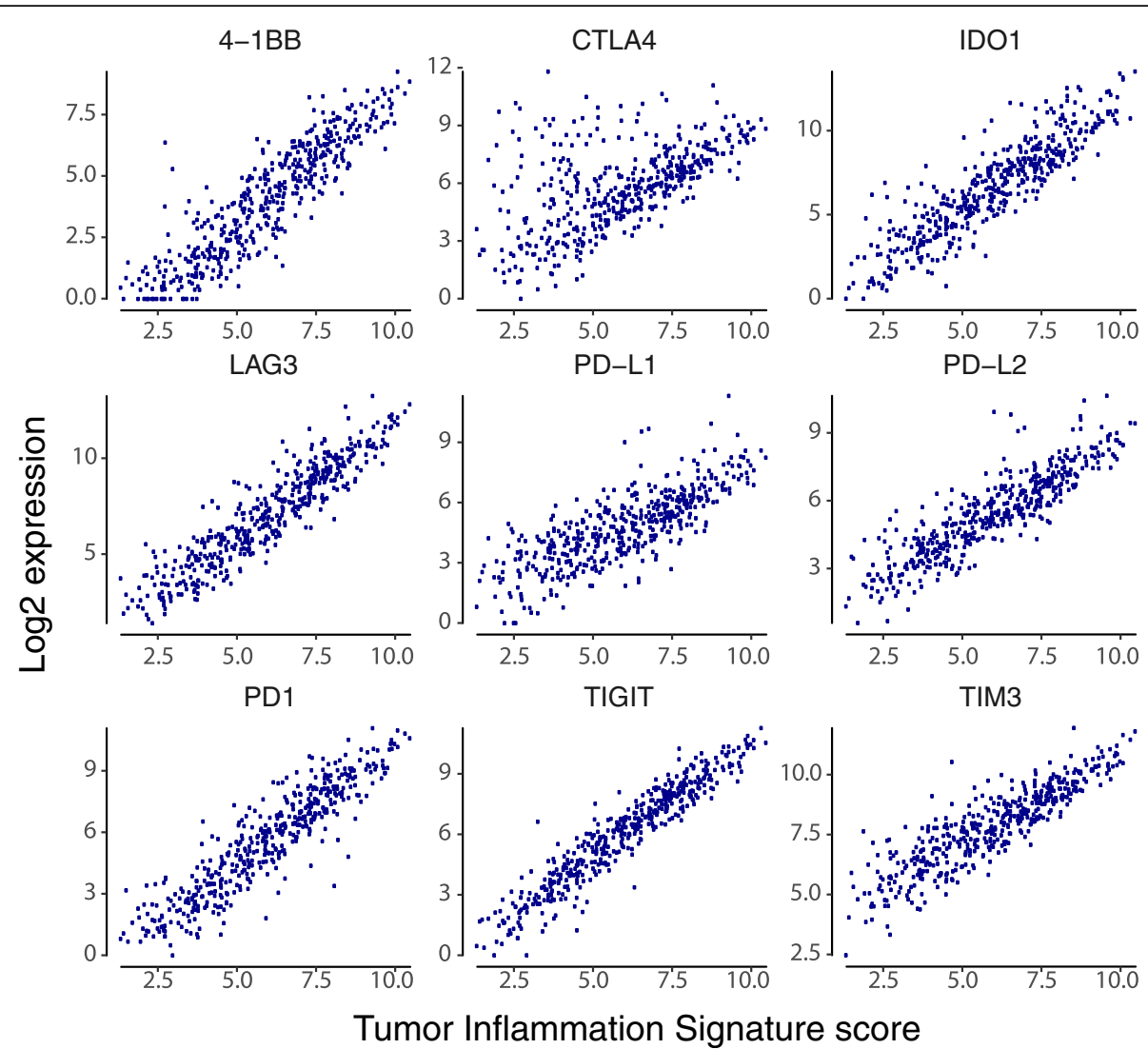

Fig. 6 Expression of immunotherapy target molecules versus TIS in melanoma. Log2 expression of drug target genes is plotted against TIS scores in the TCGA melanoma dataset

tumor types. TIS score and PD-L1 are correlated, but not redundant: at any given TIS score, PDL1 (CD274) has an expression range of approximately $4 \log 2$-units, or 16-fold on the linear scale. One potential explanation for this may be specific post-transcriptional regulation of immune checkpoint molecules, e.g., loss of miRNA binding sites via 3' UTR deletion of the PD-L1 transcript 26].

Alongside the general trend for all checkpoint genes to be highly correlated with TIS scores in all cancers, there are cancer types in which a subset of patients has high expression of a checkpoint gene despite low TIS scores. Notable instances of this pattern are shown in Fig. 7.

\section{Discussion}

It is now recognized that the immune system can be monitored and the results used to guide therapeutic decisions [42]. Using gene-expression profiling signatures, 2 major subsets of advanced solid tumors can be identified: those with a $\mathrm{T}$ cell inflamed tumor microenvironment, which have a signature of a pre-existing adaptive immune response, and non- $\mathrm{T}$ cell inflamed tumors, which lack evidence of a pre-existing adaptive immune response [43].

In the context of the current treatment landscape (i.e., checkpoint inhibitors) the tumor inflamed phenotype has been associated with response to these agents, e.g., $[12,33,44,45]$; therefore, understanding whether a tumor has an inflamed or non-inflamed phenotype should be the starting point in the immunologic characterization of any tumor samples.

Currently there are no analytically and clinically validated gene expression-based tests for clinical use measuring tumor cell inflammation, although there have been previous efforts to characterize immune responses in tumors based on transcriptional profiling. Rooney et al. [15] use a set of genes associated with cytolytic activity to rank-order tumor types by immune response in a way that substantially agrees with our own approach. Two independent groups, Coppola et al. [16] and Bindea et al. [46] also use gene expression profiling to characterize immune response within colorectal cancer, but these patterns of gene expression have not been extended beyond CRC and have not been associated with response to immunotherapy. 

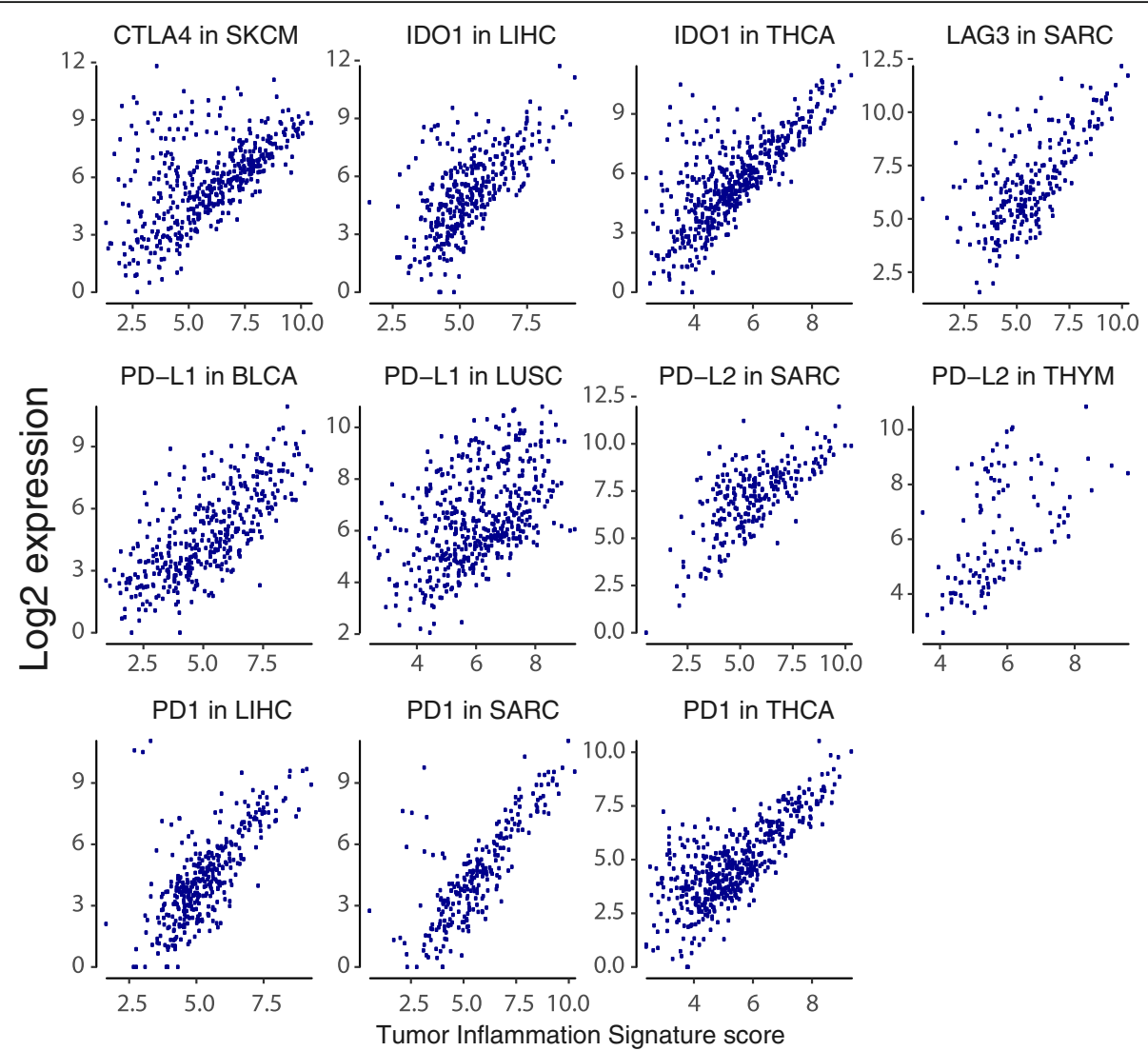

Fig. 7 Instances of a subtype with high checkpoint expression but low TIS scores

The TIS is an IUO 18-gene signature that detects an adaptive immune response within tumors by measuring expression of genes associated with cytotoxic cells, antigen presentation, and interferon gamma (IFN $\gamma$ ) activity [47]. The TIS has previously been shown to enrich for a population of patients who respond to the anti-PD1 agent pembrolizumab and has been analytically validated as a clinical trial assay for investigational use only and has been tested retrospectively in clinical trials $[12,47]$. Since the genes in the signature measure immune-intrinsic transcriptomic activity with minimal contribution of tumor-intrinsic gene expression, the signature may prove to be pan-cancer or tumor-type agnostic. In the present study we applied the TIS across a range of tumor gene expression data downloaded from the TCGA in order to characterize the immune profile of a wide range of immunotherapy-naïve tumor types.

As expected, we found that tumors with greater sensitivity to anti-PD-1 blockade tend to have higher average TIS scores. The tumor ranking we observed is comparable with that obtained by Spranger et al. (2016) [48], who interrogated TCGA across 30 solid tumor types with a 160-gene expression signature for T-cell inflammation. In that work, a wide range of abundance of the
T cell-inflamed tumor microenvironment gene signature was observed both within and across tumor types, with the highest fraction seen in clear cell kidney cancer and lung adenocarcinoma. Our work generated similar results; however, since the genes in the Spranger signature have not been published, direct comparison is not possible. Furthermore, since the TIS (reagents, instrumentation, algorithm and software) has been analytically developed as an IUO diagnostic assay, it may be prospectively deployed for patient selection in clinical trials.

Notably, TIS genes have highly conserved co-expression patterns across tumor types, consistent with a model in which the genes measure immune phenotype independent of the tumor cell of origin. In addition, while TIS scores are higher in classically immunogenic tumor types, they display a significant amount of intersample variability within most tumor types, and a subset of patients can be identified who possess elevated TIS scores, consistent with responsiveness to anti-PD-1 blockade, in all tumor types but with different prevalence. These findings raise the possibility that TIS, much like MSI/dMMR, could be used as pan-tumor biomarker enriching for patients likely to respond to single agent anti-PD-1/PD-L1 treatment. Furthermore, by simultaneously evaluating expression of 
other immune checkpoints relative to TIS expression, it may be possible to identify tumors with high checkpoint expression/low TIS score that are candidates for responding to the "right" checkpoint inhibitor despite being "immune cold", as measured by TIS score.

Mutation load has been shown in retrospective analysis to be a predictive biomarker for clinical benefit from single-agent anti-PD-1/PD-L1 agents in certain tumor types such as melanoma, NSCLC, bladder, and HNSCC [9, 49-51]. Similarly, TIS's association with clinical benefit (i.e. reduction in tumor burden) from the same agents has been shown in many of the same tumor types [12, 51-53]. Notably, our study found only weak correlation between TIS scores and mutation load; although this is consistent with previous observations from others $[48,54]$, it also suggests that the 2 biomarkers are not fully overlapping and might contribute orthogonal information in certain tumor settings [55]. Specifically, total mutation load is a surrogate measure of the intrinsic potential tumor antigenicity (but it is "upstream" of the immune response cascade), while TIS score is a direct measure of the ongoing immune response within the tumor, but is sensitive to sampling bias due to the heterogeneity of the tumor microenvironment. A combination of the 2 biomarkers could therefore increase accuracy in identifying patients who can potentially benefit from checkpoint inhibitors.

In many cases, for example in the 3 kidney cancer types in TCGA, ranking tumor types by median TIS score showed superior association to reported clinical sensitivity to PD-1/PD-L1 blockade than ranking of the same tumors by mutation load; thus, in tumor types with limited variability of mutation burden, TIS may have more predictive power than other profiling techniques. For instance, in head and neck tumors, some cases are caused by smoking and will have high mutation loads, but some cases are caused by human papillomavirus (HPV) and would have immune responses directed against the viral antigens. As shown by Haddad and colleagues (2017) [51], TIS predictive value in the context of single agent pembrolizumab is independent from HPV infection status while mutation load is only predictive in HPV negative tumors. Similarly, cervical tumors are also associated with HPV. These tumors would be expected to have high TIS and low mutation load, and this can be seen in the data (CESC and HNSC, Fig. 2).

TIS appears to be minimally prognostic in most, but not all cancers, perhaps due to the immune evasion strategies that must be established in order for the tumor to grow to the size that it is clinically detectable. This finding supports interpretation of TIS in single-arm clinical trials: if a survival benefit is seen in high TIS patients, it likely results from improved response to the drug and not to an inherent survival benefit of high TIS. In an important exception, this assumption does not apply in melanoma, where TIS was highly statistically significantly prognostic. TIS was also positively prognostic in bladder carcinomas, cervical carcinomas, and sarcomas. In these cancers, trials in high-TIS patients will suffer attenuated power if the placebo arm displays better survival than historical data [56]. The tumor types in which TIS score is negatively prognostic (kidney papillary, pancreatic, glioma) are known to be resistant to PD-1 therapy, and the prevalence of TIS positivity in these tumors is low. In contrast to the limited prognostic power of TIS, Ayers et al. reported that TIS was associated with objective response to pembrolizumab across a variety of tumors, so TIS has potential pan-cancer applicability in predicting response to PD-1 checkpoint blockade [12].

Finally, to screen for novel suppressive mechanisms, this study searched for biological pathways associated with low TIS scores. Metabolism, ribosomal, and telomere-associated pathways all predicted lower TIS scores in multiple cancer types. No targetable oncogenic pathways were associated with TIS.

This study has several technical limitations. The TIS algorithm is an investigational assay on the NanoString nCounter platform that was developed with data from clinical trials of the checkpoint inhibitor pembrolizumab, whereas TCGA samples were profiled using RNAseq from biopsies taken at diagnosis. Data from the nCounter-based assay differs from TCGA RNASeq data in several ways: in the NanoString assay, a different platform is used to measure gene expression, patient sample data are normalized to an in-vitro transcribed RNA reference sample to control for technical effects, FFPE tissue is used, and tissues with $<50 \%$ tumor are macrodissected. To the extent that these differences influence gene expression measurements by changing probe efficiencies, a reasonable model for most of the effects, TCGA TIS scores will only be shifted by a constant from what the TIS assay would have returned from the same tissues. The effect of different macrodissection protocols, however, is variable and hard to predict, and could plausibly cause more complex inter-assay TIS score differences.

Another limitation of the current study is that it relies upon the early stage tumors that were collected in the TCGA cohort and thus may not be well matched to the late stage disease where immunotherapy is being applied clinically today. However, at the time of this work, large publicly available gene expression profiling datasets of late stage cancer cohorts are not available. Furthermore, clinical trials in immunotherapy are being deployed earlier in the course of disease where the TCGA cohort is more representative of the clinical population. 
Despite these limitations, this analysis of TCGA data shows the value (both from a mechanistic and a clinical point of view) of analytically validated gene expression signature measuring the level of $\mathrm{T}$ cell inflammation as an immune-phenotyping tool across different histologically defined tumor types. It also highlights the need for broader characterization of the mechanisms of immune evasions operating within the $\mathrm{T}$ cell inflamed and non-inflamed tumors, ideally in the same assay, maximizing the clinically actionable information extractable from a single tumor sample.

\section{Additional files}

Additional file 1: Figure S7. Distribution of TIS scores in stage IV disease. TIS scores are shown for all TCGA patients with stage 4 disease. Cancer types are ordered by median TIS score in all patients, identical to Fig. 1. (PDF $30 \mathrm{~kb}$ )

Additional file 2: Figure S1. Meta-analysis of TIS score with objective response rates. [21, 50, 57-106]. (PDF 6 kb)

Additional file 3: Figure S6. Distribution of TIS scores within two MSI status categories and three cancer types. Points show individual samples' TIS scores. (PDF $31 \mathrm{~kb}$ )

Additional file 4: Figure S2. In order to assess whether/how cancer cell of origin could directly affect the expression of TIS genes, the observed expression level for each gene versus the expected expression level based on total TIS score was evaluated. Specifically, for each algorithm gene, a linear mixed model (LMM) was fit predicting the gene's log2 expression from TIS score and cancer type, with cancer type modelled as a random effect. The LMM's variance term for cancer type was compared to each gene's marginal variance across TCGA datasets. (PDF $4 \mathrm{~kb}$ )

Additional file 5: Figure S4. GO terms with the strongest negative association with TIS. Color shows GSA score. (PDF $16 \mathrm{~kb}$ )

Additional file 6: Table S1. For each cancer type, GO terms with negative associations with TIS, defined as a GSA score below - 1. (CSV 48 kb)

Additional file 7: Figures. S8-S39. Checkpoints versus TIS score in all tumor types. (PDF $701 \mathrm{~kb}$ )

Additional file 8: Figure S3. Volcano plot showing association between single genes and TIS in TCGA SKCM. (PDF 1092 kb)

Additional file 9: Figure S5. Association between TIS score and breast cancer survival. Breast cancers were divided in 4 subsets based on their TIS scores. Kaplan-Meier curves and confidence intervals are shown for each subset. (PDF $17 \mathrm{~kb}$ )

\section{Acknowledgements}

The authors thank Christine Dale for help with manuscript preparation.

\section{Funding}

Support for data collection, analysis, and manuscript writing was provided by research funds from NanoString Technologies.

\section{Availability of data and materials}

All data generated or analysed during this study are included in this published article [and its Additional files].

\section{Authors' contributions}

PD, SW, and AC conceived and designed the experiments; PD performed the experiments; PD, SW, and AC analyzed the data; AS, IP, and BW contributed reagents/materials/analysis tools; $\mathrm{RL}, J \mathrm{~S}$, and FMM reviewed the paper. All authors read and approved the final manuscript.

Ethics approval and consent to participate

Not applicable.

\section{Competing interests}

P.D., S.W., A.S., I.P., B.W., and A.C. are employees and shareholders of NanoString Technologies. R.L, J.S., and F.M.M. are employees of AbbVie Biotherapeutics.

\section{Publisher's Note}

Springer Nature remains neutral with regard to jurisdictional claims in published maps and institutional affiliations.

\section{Author details}

${ }^{1}$ NanoString Technologies Inc, Seattle, WA, USA. ${ }^{2}$ AbbVie Inc., Redwood City, CA, USA.

Received: 2 March 2018 Accepted: 25 May 2018

Published online: 22 June 2018

\section{References}

1. Ma W, Gilligan BM, Yuan J, Li T. Current status and perspectives in translational biomarker research for PD-1/PD-L1 immune checkpoint blockade therapy. J Hematol Oncol. 2016;9(1):47.

2. Masucci GV, Cesano A, Hawtin R, Janetzki S, Zhang J, Kirsch I, et al. Validation of biomarkers to predict response to immunotherapy in cancer: volume I-pre-analytical and analytical validation. J Immunother Cancer. 2016;4(1):76

3. Pages F, Galon J, Dieu-Nosjean MC, Tartour E, Sautes-Fridman C, Fridman WH. Immune infiltration in human tumors: a prognostic factor that should not be ignored. Oncogene. 2010;29(8):1093.

4. Galon J, Mlecnik B, Bindea G, Angell HK, Berger A, Lagorce C, et al. Towards the introduction of the 'Immunoscore'in the classification of malignant tumours.J Pathol. 2014:232(2):199-209.

5. Mlecnik B, Bindea G, Angell HK, Maby P, Angelova M, Tougeron D, et al. Integrative analyses of colorectal cancer show immunoscore is a stronger predictor of patient survival than microsatellite instability. Immunity. 2016;44(3):698-711.

6. FDA Approves Merck's KEYTRUDA ${ }^{\circledast}$ (pembrolizumab) for Adult and Pediatric Patients with Unresectable or Metastatic, Microsatellite Instability-High (MSI-H) or Mismatch Repair Deficient (dMMR) Solid Tumors. Available online: http://www. mrknewsroom.com/news-release/prescription-medicine-news/fda-approvesmercks-keytruda-pembrolizumab-adult-and-pediatr. Accessed 25 Apr 2018.

7. Brahmer JR, Drake CG, Wollner I, Powderly JD, Picus J, Sharfman WH, et al. Phase I study of single-agent anti-programmed death-1 (MDX-1106) in refractory solid tumors: safety, clinical activity, pharmacodynamics, and immunologic correlates. J Clin Oncol. 2010;28(19):3167.

8. Diaz LA, Marabelle A, Delord JP, Shapira-Frommer R, Geva R, Peled N, Kim TW, Andre T, Van Cutsem E, Guimbaud R, Jaeger D. Pembrolizumab therapy for microsatellite instability high (MSI-H) colorectal cancer (CRC) and nonCRC. J Clin Oncol. 2017;35(15_suppl):3071. https://doi.org/10.1200/JCO.2017. 35.15 suppl.3071.

9. Rizvi NA, Hellmann MD, Snyder A, Kvistborg P, Makarov V, Havel JJ, et al. Mutational landscape determines sensitivity to PD-1 blockade in non-small cell lung cancer. Science. 2015;348(6230):124-8.

10. Yarchoan M, Hopkins A, Jaffee EM. Tumor mutational burden and response rate to PD-1 inhibition. NEJM. 2017:377(25):2500-1.

11. Chalmers ZR, Connelly CF, Fabrizio D, Gay L, Ali SM, Ennis R, et al. Analysis of 100,000 human cancer genomes reveals the landscape of tumor mutational burden. Genome Med. 2017;9(1):34.

12. Ayers M, Lunceford J, Nebozhyn M, Murphy E, Loboda A, Kaufman DR, et al IFN- $\gamma$-related mRNA profile predicts clinical response to PD-1 blockade. J Clin Invest. 2017:127(8):2930-40.

13. Higgs BW, Morehouse CA, Streicher K, Brohawn PZ, Steele K, Rebelatto M, et al. A baseline IFNG gene expression signature correlates with clinical outcomes in durvalumab-treated advanced NSCLC cancer patients. In: Proc Amer Assoc Cancer Res. 2017;77(13 Suppl): Abstract 1773.

14. Fehrenbacher L, Spira A, Ballinger M, Kowanetz M, Vansteenkiste J, Mazieres J, et al. Atezolizumab versus docetaxel for patients with previously treated non-small-cell lung cancer (POPLAR): a multicentre, open-label, phase 2 randomised controlled trial. Lancet. 2016; 387(10030):1837-46.

15. Rooney MS, Shukla SA, Wu CJ, Getz G, Hacohen N. Molecular and genetic properties of tumors associated with local immune cytolytic activity. Cell. 2015;160(1-2):48-61. 
16. Coppola D, Nebozhyn M, Khalil F, Dai H, Yeatman T, Loboda A, et al. Unique ectopic lymph node-like structures present in human primary colorectal carcinoma are identified by immune gene array profiling. Am J Pathol. 2011; 179(1):37-45.

17. Galon J, Angell HK, Bedognetti D, Marincola FM. The continuum of cancer immunosurveillance: prognostic, predictive, and mechanistic signatures. Immunity. 2013;39(1):11-26.

18. Efron B, Tibshirani R. On testing the significance of sets of genes. Ann Appl Statistics. 2007;1(1):107-29.

19. Ashburner M, Ball CA, Blake JA, Botstein D, Butler H, Cherry JM, et al. Gene ontology: tool for the unification of biology. Nature Genet. 2000;25(1):25.

20. Subramanian A, Tamayo P, Mootha VK, Mukherjee S, Ebert BL, Gillette MA, et al. Gene set enrichment analysis: a knowledge-based approach for interpreting genome-wide expression profiles. Proc Natl Acad Sci U S A. 2005;102(43):15545-50

21. Motzer RJ, Escudier B, McDermott DF, George S, Hammers HJ, Srinivas S, et al. D. Nivolumab versus everolimus in advanced renal-cell carcinoma. NEJM. 2015;373(19):1803-13. https://doi.org/10.1056/NEJMoa1510665.

22. Topalian SL, Sznol M, McDermott DF, Kluger HM, Carvajal RD, Sharfman WH, et al. Survival, durable tumor remission, and long-term safety in patients with advanced melanoma receiving nivolumab. J Clin Oncol. 2014;32(10): 1020-30. https://doi.org/10.1200/JCO.2013.53.0105.

23. Reck M, Rodríguez-Abreu D, Robinson AG, Hui R, Csőszi T, Fülöp A, et al. Pembrolizumab versus chemotherapy for PD-L1-positive non-small-cell lung cancer. NEJM. 2016;375(19):1823-33. https://doi.org/10.1056/ NEJMoa1606774

24. Ferris RL, Blumenschein G Jr, Fayette J, Guigay J, Colevas AD, et al. Nivolumab for recurrent squamous-cell carcinoma of the head and neck. NEJM. 2016;375(19):1856-67. https://doi.org/10.1056/NEJMoa1602252.

25. Fyfe G, Fisher RI, Rosenberg SA, Sznol M, Parkinson DR, Louie AC. Results of treatment of 255 patients with metastatic renal cell carcinoma who received high-dose recombinant interleukin-2 therapy. J Clin Oncol. 1995;13(3):688-96.

26. Minasian LM, Motzer RJ, Gluck L, Mazumdar M, Vlamis V, Krown SE. Interferon alfa-2a in advanced renal cell carcinoma: treatment results and survival in 159 patients with long-term follow-up. J Clin Oncol. 1993;11(7): 1368-75.

27. Motzer RJ, Rini BI, McDermott DF, Redman BG, Kuzel TM, Harrison MR, Vaishampayan UN, Drabkin HA, George S, Logan TF, Margolin KA Nivolumab for metastatic renal cell carcinoma: results of a randomized phase II trial. J Clin Oncol. 2014;33(13):1430-7.

28. Moreira RB, McKay RR, Xie W, Heng DY, de Velasco G, Castellano DE, et al. Clinical activity of PD1/PDL1 inhibitors in metastatic non-clear cell renal cell carcinoma (nccRCC). Journal of Clinical Oncology. 2017;35(6_suppl):482. https://doi.org/10.1200/JCO.2017.35.6_suppl.482.

29. Koshkin VS, Barata PC, Zhang T, George DJ, Atkins MB, Kelly WJ, et al. Clinical activity of nivolumab in patients with non-clear cell renal cell carcinoma. J Immunother Cancer. 2018;6(1):9.

30. Şenbabaoğlu Y, Gejman RS, Winer AG, Liu M, Van Allen EM, de Velasco G, et al. Tumor immune microenvironment characterization in clear cell renal cell carcinoma identifies prognostic and immunotherapeutically relevant messenger RNA signatures. Genome Biol. 2016;17(1):231.

31. Ugel S, De Sanctis F, Mandruzzato S, Bronte V. Tumor-induced myeloid deviation: when myeloid-derived suppressor cells meet tumor-associated macrophages. J Clin Invest. 2015;125(9):3365-76.

32. Hsu DS, Kim MK, Balakumaran BS, Acharya CR, Anders CK, Clay T, et al. Immune signatures predict prognosis in localized cancer. Cancer Investig. 2010;28(7):765-73.

33. Galon J, Costes A, Sanchez-Cabo F, Kirilovsky A, Mlecnik B, Lagorce-Pagès C, et al. Type, density, and location of immune cells within human colorectal tumors predict clinical outcome. Science. 2006;313:1960-4.

34. Diederichsen AC, Hjelmborg JB, Christensen PB, Zeuthen J, Fenger C. Prognostic value of the CD4+/CD8+ ratio of tumour infiltrating lymphocytes in colorectal cancer and HLA-DR expression on tumour cells. Cancer Immunol Immunother. 2003;52:423-8.

35. Sivendran S, Chang R, Pham L, Phelps RG, Harcharik ST, Hall LD, et al. Dissection of immune gene networks in primary melanoma tumors critical for antitumor surveillance of patients with stage II-III resectable disease. J Invest Dermatol. 2014;134(8):2202-11.

36. Benjamini $Y$, Hochberg Y. Controlling the false discovery rate: a practical and powerful approach to multiple testing. J Royal Stat Soc Series B (Methodological). 1995;57(1):289-300.
37. Parker JS, Mullins M, Cheang MC, Leung S, Voduc D, Vickery T, et al. Supervised risk predictor of breast cancer based on intrinsic subtypes. J Clin Oncol. 2009;27(8):1160-7. https://doi.org/10.1200/JCO.2008.18.1370.

38. Hendrickx W, Simeone I, Anjum S, Mokrab Y, Bertucci F, Finetti P, et al. Identification of genetic determinants of breast cancer immune phenotypes by integrative genome-scale analysis. Oncolmmunol. 2017;6(2):e1253654

39. Cleveland WS. Robust locally weighted regression and smoothing scatterplots. J Am Stat Assoc. 1979;74(368):829-36.

40. Danaher P, Warren S, Dennis L, D'Amico L, White A, Disis ML, et al. Gene expression markers of tumor infiltrating leukocytes. J Immunother Cancer. 2017;5(1):18.

41. Bekisz J, Baron S, Balinsky C, Morrow A, Zoon KC. Antiproliferative properties of type I and type II interferon. Pharmaceuticals. 2010;3(4):994-1015.

42. Chen DS, Mellman I. Oncology meets immunology: the cancer-immunity cycle. Immunity. 2013;39(1):1-10.

43. Gajewski TF, Fuertes M, Spaapen R, Zheng Y, Kline J. Molecular profiling to identify relevant immune resistance mechanisms in the tumor microenvironment. Curr Opin Immunol. 2011;23(2):286-92.

44. Tumeh PC, Harview CL, Yearley JH, Shintaku IP, Taylor EJ, Robert L, et al. PD-1 blockade induces responses by inhibiting adaptive immune resistance. Nature. 2014;515(7528):568-71.

45. Ji RR, Chasalow SD, Wang L, Hamid O, Schmidt H, Cogswell J, et al. An immune-active tumor microenvironment favors clinical response to ipilimumab. Cancer Immunol Immunother. 2012;61(7):1019-31.

46. Bindea G, Mlecnik B, Tosolini M, Kirilovsky A, Waldner M, Obenauf AC, et al. Spatiotemporal dynamics of intratumoral immune cells reveal the immune landscape in human cancer. Immunity. 2013;39(4):782-95.

47. Ayers M, Lunceford J, Nebozhyn M, Murphy E, Loboda A, Albright A, et al. Relationship between immune gene signatures and clinical response to PD1 blockade with pembrolizumab (MK-3475) in patients with advanced solid tumors. J Immunother Cancer. 2015;3(Suppl 2):80.

48. Spranger S, Luke JJ, Bao R, Zha Y, Hernandez KM, Li Y, et al. Density of immunogenic antigens does not explain the presence or absence of the T-cell-inflamed tumor microenvironment in melanoma. Proc Natl Acad Sci U S A. 2016;113(48):E7759-E7768.

49. Van Allen EM, Miao D, Schilling B, Shukla SA, Blank C, Zimmer L, et al. Genomic correlates of response to CTLA-4 blockade in metastatic melanoma. Science. 2015;350(6257):207-11.

50. Rosenberg JE, Hoffman-Censits J, Powles T, Van Der Heijden MS, Balar AV, Necchi A, et al. Atezolizumab in patients with locally advanced and metastatic urothelial carcinoma who have progressed following treatment with platinum-based chemotherapy: a single-arm, multicentre, phase 2 trial. Lancet. 2016;387(10031):1909-20.

51. Haddad RI, Seiwert TY, Chow LQ, Gupta S, Weiss J, Gluck I, et al. Genomic determinants of response to pembrolizumab in head and neck squamous cell carcinoma (HNSCC). J Clin Oncol. 2017;35(15_suppl):6009.

52. O'Donnell PH, Grivas P, Balar AV, Bellmunt J, Vuky J, Powles T, et al. Biomarker findings and mature clinical results from KEYNOTE-052: first-line pembrolizumab (pembro) in cisplatin-ineligible advanced urothelial cancer (UC). J Clin Oncol. 2017;35(15_suppl):4502.

53. Piha-Paul SA, Bennouna J, Albright A, Nebozhyn M, McClanahan T, Ayers M, et al. T-cell inflamed phenotype gene expression signatures to predict clinical benefit from pembrolizumab across multiple tumor types. J Clin Oncol. 2016; 34(15_suppl):1536. https://doi.org/10.1200/JCO.2016.34.15_suppl.1536.

54. Rieke DT, Messerschmidt C, Ochsenreither S, Klinghammer KF, Tinhofer I, Jöhrens K, et al. Association of an APOBEC mutational signature, mutational load, and BRCAness with inflammation and PD-L1 expression in HNSCC. J Clin Oncol. 2017;35(15_suppl):e14613.

55. Cristescu R, Mogg R, Ayers M, Albright A, Murphy E, Yearley J, et al. Tumor mutational load and T-cell inflamed microenvironment are independent determinants of response to pembrolizumab. Presented at ASCO-SITC Clinical Immuno-Oncology Symposium Orlando, FL, USA, February 23-25, 2017. (https://meetinglibrary.asco.org/record/144493/abstract).

56. Powles T, Loriot Y, Duran I. IMvigor211: a phase III randomized study examining atezolizumab vs. chemotherapy for platinum-treated advanced urothelial carcinoma. In: 2nd special conference EACR AACR SIC; 2017.

57. Adra N, Althouse SK, Ammakkanavar NR, Radovich M, Albany C, Vaughn DJ, et al. Phase II trial of pembrolizumab in patients (pts) with incurable platinum refractory germ cell tumors (GCT). J Clin Oncol. 2017;35:4520. 
58. Algazi AP, Tsai KK, Shoushtari AN, Munhoz RR, Eroglu Z, Piulats JM, et al. Clinical outcomes in metastatic uveal melanoma treated with PD-1 and PDL1 antibodies. Cancer. 2016;122:3344-53.

59. Apolo AB, Infante JR, Balmanoukian A, Patel MR, Wang D, Kelly K, et al. Avelumab, an anti-programmed death-ligand 1 antibody, in patients with refractory metastatic urothelial carcinoma: results from a multicenter, phase Ib study. J Clin Oncol. 2017;35:2117-24.

60. Bauml J, Seiwert TY, Pfister DG, Worden F, Liu SV, Gilbert J, et al. Pembrolizumab for platinum-and cetuximab-refractory head and neck cancer: results from a single-arm, phase II study. J Clin Oncol. 2017;35(14):1542-9.

61. Bellmunt J, De Wit R, Vaughn DJ, Fradet $Y$, Lee JL, Fong L, et al. Pembrolizumab as second-line therapy for advanced urothelial carcinoma. NEJM. 2017;376(11):1015-26.

62. Brahmer J, Reckamp KL, Baas P, Crinò L, Eberhardt WE, Poddubskaya E, et al. Nivolumab versus docetaxel in advanced squamous-cell non-small-cell lung cancer. NEJM. 2015;373(2):123-35.

63. Brahmer JR, Tykodi SS, Chow LQ, Hwu WJ, Topalian SL, Hwu P, et al. Safety and activity of anti-PD-L1 antibody in patients with advanced cancer. NEJM. 2012;366(26):2455-65.

64. Chung HC, Arkenau HT, Wyrwicz L, Oh DY, Lee KW, Infante JR. Avelumab (MSB0010718C; anti-PD-L1) in patients with advanced gastric or gastroesophageal junction cancer from JAVELIN solid tumor phase Ib trial: analysis of safety and clinical activity. J Clin Oncologia. 2016;34:4009.

65. D'Angelo SP, Mahoney MR, Van Tine BA, Atkins JN, Milhem MM, Tap WD, et al. A multi-center phase II study of nivolumab+/-ipilimumab for patients with metastatic sarcoma (alliance A091401). J Clin Oncol. 2017; 35:-11007.

66. Diaz L, Marabelle A, Kim TW, Geva R, Van Cutsem E, André T, et al. Efficacy of pembrolizumab in phase 2 KEYNOTE-164 and KEYNOTE-158 studies of microsatellite instability high cancers. Ann Oncol 2017; 28(suppl_5), Abstract 386P.

67. Dirix LY, Takacs I, Jerusalem G, Nikolinakos P, Arkenau HT, Forero-Torres A, et al. Avelumab, an anti-PD-L1 antibody, in patients with locally advanced or metastatic breast cancer: a phase $1 \mathrm{~b}$ JAVELIN solid tumor study. Breast Cancer Res Tr. 2018:167(3):671-86.

68. Disis ML, Patel MR, Pant S, Hamilton EP, Lockhart AC, Kelly K, et al. Avelumab (MSB0010718C; anti-PD-L1) in patients with recurrent/refractory ovarian cancer from the JAVELIN solid tumor phase Ib trial: safety and clinical activity. J Clin Oncol. 2016;34:5533. https://doi.org/10.1200/JCO.2016.34.15_suppl.5533.

69. El-Khoueiry AB, Sangro B, Yau T, Crocenzi TS, Kudo M, Hsu C, et al. Nivolumab in patients with advanced hepatocellular carcinoma (CheckMate 040): an open-label, non-comparative, phase 1/2 dose escalation and expansion trial. Lancet. 2017;389(10088):2492-502.

70. Fakhrejahani F, Madan RA, Dahut WL, Karzai F, Cordes LM, Schlom J, et al. Avelumab in metastatic castration-resistant prostate cancer (mCRPC). J Clin Oncol. 2017:35:159. https://doi.org/10.1200/JCO.2017.35.6.

71. Ferris RL, Blumenschein G Jr, Fayette J, Guigay J, Colevas AD, Licitra L, et al. Nivolumab for recurrent squamous-cell carcinoma of the head and neck. NEJM. 2016;375(19):1856-67.

72. Filley AC, Henriquez M, Dey M. Recurrent glioma clinical trial, CheckMate143: the game is not over yet. Oncotarget. 2017:8(53):91779.

73. Fleming GF, Emens LA, Eder JP, Hamilton EP, Liu JF, Liu B, et al. Clinical activity, safety and biomarker results from a phase la study of atezolizumab (atezo) in advanced/recurrent endometrial cancer (rEC). J Clin Oncol. 2017; 35:5585. https://doi.org/10.1200/JCO.2017.35.15_suppl.5585.

74. Fuchs CS, Doi T, Jang RW, Muro K, Satoh T, Machado M, et al. KEYNOTE-059 cohort 1: efficacy and safety of pembrolizumab (pembro) monotherapy in patients with previously treated advanced gastric cancer. J Clin Oncol. 2017; 35:4003. DOI: 10.1200/JCO.2017.35.15_suppl.4003

75. Garon EB, Rizvi NA, Hui R, Leighl N, Balmanoukian AS, Eder JP, et al. Pembrolizumab for the treatment of non-small-cell lung cancer. NEJM. 2015;372(21):2018-28.

76. Graff JN, Alumkal JJ, Drake CG, Thomas GV, Redmond WL, Farhad M, et al. Early evidence of anti-PD-1 activity in enzalutamide-resistant prostate cancer. Oncotarget. 2016;7(33):52810.

77. Gulley JL, Rajan A, Spigel DR, lannotti N, Chandler J, Wong DJ, et al. Avelumab for patients with previously treated metastatic or recurrent non-small-cell lung cancer (JAVELIN solid tumor): dose-expansion cohort of a multicentre, open-label, phase 1b trial. Lancet Oncol. 2017;18(5): 599-610.
78. Hamanishi J, Mandai M, Ikeda T, Minami M, Kawaguchi A, Murayama T, et al. Safety and antitumor activity of anti-PD-1 antibody, nivolumab, in patients with platinum-resistant ovarian cancer. J Clin Oncol. 2015;33(34):4015-22.

79. Hassan R, Thomas A, Patel MR, Nemunaitis JJ, Bennouna J, Powderly JD, et al. Avelumab (MSB0010718C; anti-PD-L1) in patients with advanced unresectable mesothelioma from the JAVELIN solid tumor phase lb trial: safety, clinical activity, and PD-L1 expression. J Clin Oncol 2016;34:8503. DOI: https://doi.org/10.1200/JCO.2016.34.15_suppl.8503.

80. Hellmann MD, Ott PA, Zugazagoitia J, Ready NE, Hann CL, De Braud FG, et al. Nivolumab (nivo) \pm ipilimumab (ipi) in advanced small-cell lung cancer (SCLC): first report of a randomized expansion cohort from CheckMate 032. J Clin Oncol. 2017;35:8503. https://doi.org/10.1200/JCO.2017.35.15_suppl.8503.

81. Hollebecque A, Meyer T, Moore KN, Machiels JP, De Greve J, López-Picazo JM, et al. An open-label, multicohort, phase I/II study of nivolumab in patients with virus-associated tumors (CheckMate 358): efficacy and safety in recurrent or metastatic (R/M) cervical, vaginal, and vulvar cancers. J Clin Oncol. 2017:35:5504. https://doi.org/10.1200/JCO.2017.35.15 suppl.5504.

82. Kang YK, Boku N, Satoh T, Ryu MH, Chao Y, Kato K, et al. Nivolumab in patients with advanced gastric or gastro-oesophageal junction cancer refractory to, or intolerant of, at least two previous chemotherapy regimens (ONO-4538-12, ATTRACTION-2): a randomised, double-blind, placebocontrolled, phase 3 trial. Lancet. 2017;390(10111):2461-71.

83. Kaufman HL, Russell JS, Hamid O, Bhatia S, Terheyden P, D'Angelo SP, et al. Durable responses to avelumab (anti-PD-L1) in patients with Merkel cell carcinoma progressed after chemotherapy: 1-year efficacy update. In: Proceedings of the 107th Annual Meeting of the American Association for Cancer Research. Washington, DC: Cancer Research. 2017;77(13):CT079.

84. Koshkin VS, Barata PC, Zhang T, George DJ, Atkins MB, Kelly WJ, et al. Clinical activity of nivolumab in patients with non-clear cell renal cell carcinoma. J Immunother Cancer. 2018;6(1):9. https://doi.org/10.1186/s40425-018-0319-9.

85. Larkin J, Chiarion-Sileni V, Gonzalez R, Grob JJ, Cowey CL, Lao CD, et al. Combined nivolumab and ipilimumab or monotherapy in untreated melanoma. NEJM. 2015;373(1):23-34.

86. Le DT, Uram JN, Wang H, Bartlett BR, Kemberling H, Eyring AD, et al. PD-1 blockade in tumors with mismatch-repair deficiency. NEJM. 2015;372(26):2509-20.

87. Le Tourneau C, Zarwan C, Hoimes C, Wong DJ, Bauer S, Wermke M, et al. Avelumab in patients with metastatic adrenocortical carcinoma (mACC): results from the JAVELIN solid tumor trial. Ann Oncol. 2017;28(suppl_5) Abstract 913P. https://doi.org/10.1093/annonc/mdx371.067

88. McDermott DF, Sosman JA, Sznol M, Massard C, Gordon MS, Hamid O, et al. Atezolizumab, an anti-programmed death-ligand 1 antibody, in metastatic renal cell carcinoma: long-term safety, clinical activity, and immune correlates from a phase la study. J Clin Oncol. 2016;34(8):833-42.

89. Moreira RB, McKay RR, Xie W, Heng DY, de Velasco G, Castellano DE, et al. Clinical activity of PD1/PDL1 inhibitors in metastatic non-clear cell renal cell carcinoma (nccRCC). J Clin Oncol. 2017;35(6)suppl):482. https://doi.org/10. 1200/JCO.2017.35.6_suppl.482.

90. Morris VK, Salem ME, Nimeiri H, lqbal S, Singh P, Ciombor K, et al. Nivolumab for previously treated unresectable metastatic anal cancer (NCl9673): a multicentre, single-arm, phase 2 study. Lancet Oncol. 2017;18(4):446-53.

91. Nghiem PT, Bhatia S, Lipson EJ, Kudchadkar RR, Miller NJ, Annamalai L, et al. PD-1 blockade with pembrolizumab in advanced Merkel-cell carcinoma. NEJM. 2016;374(26):2542-52.

92. Overman MJ, McDermott R, Leach JL, Lonardi S, Lenz HJ, Morse MA, et al. Nivolumab in patients with metastatic DNA mismatch repair-deficient or microsatellite instability-high colorectal cancer (CheckMate 142): an openlabel, multicentre, phase 2 study. Lancet Oncol. 2017;18(9):1182-91.

93. Papadopoulos KP, Owonikoko TK, Johnson ML, Brana I, Gil-Martin M, Perez RP, et al. REGN2810: a fully human anti-PD-1 monoclonal antibody, for patients with unresectable locally advanced or metastatic cutaneous squamous cell carcinoma (CSCC) - initial safety and efficacy from expansion cohorts (ECs) of phase I study. J Clin Oncol. 2017;35:9503. https://doi.org/10.1200/JCO.2017.35.15_suppl.9503

94. Powles T, O'Donnell PH, Massard C, Arkenau HT, Friedlander TW, Hoimes CJ, et al. Efficacy and safety of durvalumab in locally advanced or metastatic urothelial carcinoma: updated results from a phase 1/2 open-label study. JAMA Oncol. 2017;3(9):e172411.

95. Reardon DA, Omuro A, Brandes AA, Rieger J, Wick A, Sepulveda J, et al. 3 Randomized phase 3 study evaluating the efficacy and safety of nivolumab vs bevacizumab in patients with recurrent glioblastoma: CheckMate 143. Neuro-Oncology. 2017;19(suppl_3):iii21. 
96. Reardon DA, Kaley TJ, Dietrich J, Lim M, Dunn GP, Gan HK, et al. Phase 2 study to evaluate the clinical efficacy and safety of MEDI4736 (durvalumab) in patients with glioblastoma (GBM). J Clin Oncol. 2017;35:2042. https://doi. org/10.1200/JCO.2016.34.15_suppl.

97. Rittmeyer A, Barlesi F, Waterkamp D, Park K, Ciardiello F, Von Pawel J, et al. Atezolizumab versus docetaxel in patients with previously treated nonsmall-cell lung cancer (OAK): a phase 3, open-label, multicentre randomised controlled trial. Lancet. 2017;389(10066):255-65.

98. Robert C, Schachter J, Long GV, Arance A, Grob JJ, Mortier L, et al. Pembrolizumab versus ipilimumab in advanced melanoma. NEJM. 2015;372(26):2521-32.

99. Schellens JH, Marabelle A, Zeigenfuss S, Ding J, Pruitt SK, Chung HC. Pembrolizumab for previously treated advanced cervical squamous cell cancer: preliminary results from the phase 2 KEYNOTE-158 study. J Clin Oncol. 2017;35:5514. https://doi.org/10.1200/JCO.2017.35.15_suppl.5514.

100. Scherpereel A, Mazieres J, Greillier L, Dô P, Bylicki O, Monnet I, et al. Secondor third-line nivolumab (Nivo) versus nivo plus ipilimumab (Ipi) in malignant pleural mesothelioma (MPM) patients: results of the IFCT-1501 MAPS2 randomized phase II trial. J Clin Oncologia. 2017;35:LBA8507. https://doi.org/ 10.1200/ JCO.2017.35.18 suppl. LBA8507.

101. Schmid P, Cruz C, Braiteh FS, Eder JP, Tolaney S, Kuter I et al. Atezolizumab in metastatic TNBC (mTNBC): Long-term clinical outcomes and biomarker analyses. Cancer Res. 2017;77(13 Supplement):2986. https://doi.org/10.1158/ 1538-7445.AM2017-2986

102. Sharma P, Retz M, Siefker-Radtke A, Baron A, Necchi A, Bedke J, et al. Nivolumab in metastatic urothelial carcinoma after platinum therapy (CheckMate 275): a multicentre, single-arm, phase 2 trial. Lancet Oncol. 2017:18(3):312-22.

103. Tawbi HA, Burgess M, Bolejack V, Van Tine BA, Schuetze SM, Hu J, et al. Pembrolizumab in advanced soft-tissue sarcoma and bone sarcoma (SARC028): a multicentre, two-cohort, single-arm, open-label, phase 2 trial. Lancet Oncol. 2017;18(11):1493-501.

104. Topalian S, Bhatia S, Hollebecque A, Awada A, De Boer JP, Kudchadkar RR. Noncomparative, open-label, multiple cohort, phase $1 / 2$ study to evaluate nivolumab (NIVO) in patients with virus-associated tumors (CheckMate 358): efficacy and safety in Merkel cell carcinoma (MCC). Cancer Res. 2017;77(13 Suppl):CT074.

105. Topalian SL, Hodi FS, Brahmer JR, Gettinger SN, Smith DC, McDermott DF, et al. Safety, activity, and immune correlates of anti-PD-1 antibody in cancer. NEJM. 2012:366(26):2443-54

106. Wainberg ZA, Segal NH, Jaeger D, Lee KH, Marshall J, Antonia SJ, et al. Safety and clinical activity of durvalumab monotherapy in patients with hepatocellular carcinoma (HCC). J Clin Oncol. 2017;35:4071.

\section{Ready to submit your research? Choose BMC and benefit from}

- fast, convenient online submission

- thorough peer review by experienced researchers in your field

- rapid publication on acceptance

- support for research data, including large and complex data types

- gold Open Access which fosters wider collaboration and increased citations - maximum visibility for your research: over $100 \mathrm{M}$ website views per year

At BMC, research is always in progress.

Learn more biomedcentral.com/submissions 